\title{
Finite element simulation of steel ring fragmentation under radial expansion
}

\author{
A. Rusinek ${ }^{\mathrm{a}, *}$, R. Zaera ${ }^{\mathrm{b}}$ \\ ${ }^{a}$ Laboratory of Physics and Mechanics of Materials, UMR CNRS 75 54, University of Metz, Ile du Saulcy, 57045 Metz Cedex, France \\ ${ }^{\mathrm{b}}$ Department of Continuum Mechanics and Structural Analysis, University Carlos III of Madrid, Avda. de la Universidad 30, \\ 28911 Leganés, Madrid, Spain
}

\begin{abstract}
This paper presents a numerical analysis of the expansion of a mild steel ring with of $50 \mathrm{~mm}$ diameter, $1 \mathrm{~mm}$ thickness and a cross section of $1 \mathrm{~mm}^{2}$. A hardening relation which takes into account strain, strain rate and temperature is proposed to define precisely the thermoviscoplastic behaviour of the material considered in the study. As a second step, an algorithm to integrate the thermoviscoplastic constitutive equations, including the hardening law, is implemented in the commercial finite element code ABAQUS/Explicit via a user subroutine. Finally, this tool is used to simulate the problem of a ring expanding radially in a broad range of strain rates, covering both low and high initial velocities (from 1 to $370 \mathrm{~m} / \mathrm{s}$ ). The aim is to analyse the effect of loading velocity on the number of fragments resulting from the multiple failure of the ring and also the influence of the hardening behaviour of the material on the number of fragments and on the failure mode of the ring, considering different values of the plastic strain hardening exponent $n_{0}$. A simple failure criterion was used, based on a critical value of the equivalent strain which depends on the hardening exponent. The numerical predictions, in perfect agreement with the experimental observations, are compared with several analytical or numerical models used to solve the same problem in other materials such as aluminium, steel or copper.
\end{abstract}

Keywords: Dynamic ring expansion; Constitutive relation; Thermoviscoplasticity; Necking; Numerical simulation

\section{Introduction}

For experimental analysis of the dynamic behaviour of materials, several kinds of tests such as tension, compression or shear may be used, although it is only the last one that allows to reach large deformations, close to $\gamma \approx 1$. Among non-conventional test which extends to large plastic strains at high strain rates, the most known is that of ring expansion. Fig. 1a shows the failure strain of a steel with mechanical properties similar to that used in this work $\left(\rho_{n}=\rho / K=13.68 \mathrm{kgm}{ }^{3} \mathrm{MPa}{ }^{1}\right.$ with $\sigma=K \bar{\varepsilon}^{\mathrm{p}^{n}}$ and $\left.K=570 \mathrm{MPa}\right)$, obtained by two different dynamic loading methods. The failure strains reached with the ring expansion test seem to be higher than those observed in dynamic tensile tests. Ductility increases monotonically with expansion velocity [1], the

\footnotetext{
${ }^{*}$ Corresponding author. Tel.: + 33387315020 ; fax: +33387315366.

E mail address: rusinek@1pmm.univ metz.fr (A. Rusinek).
} 

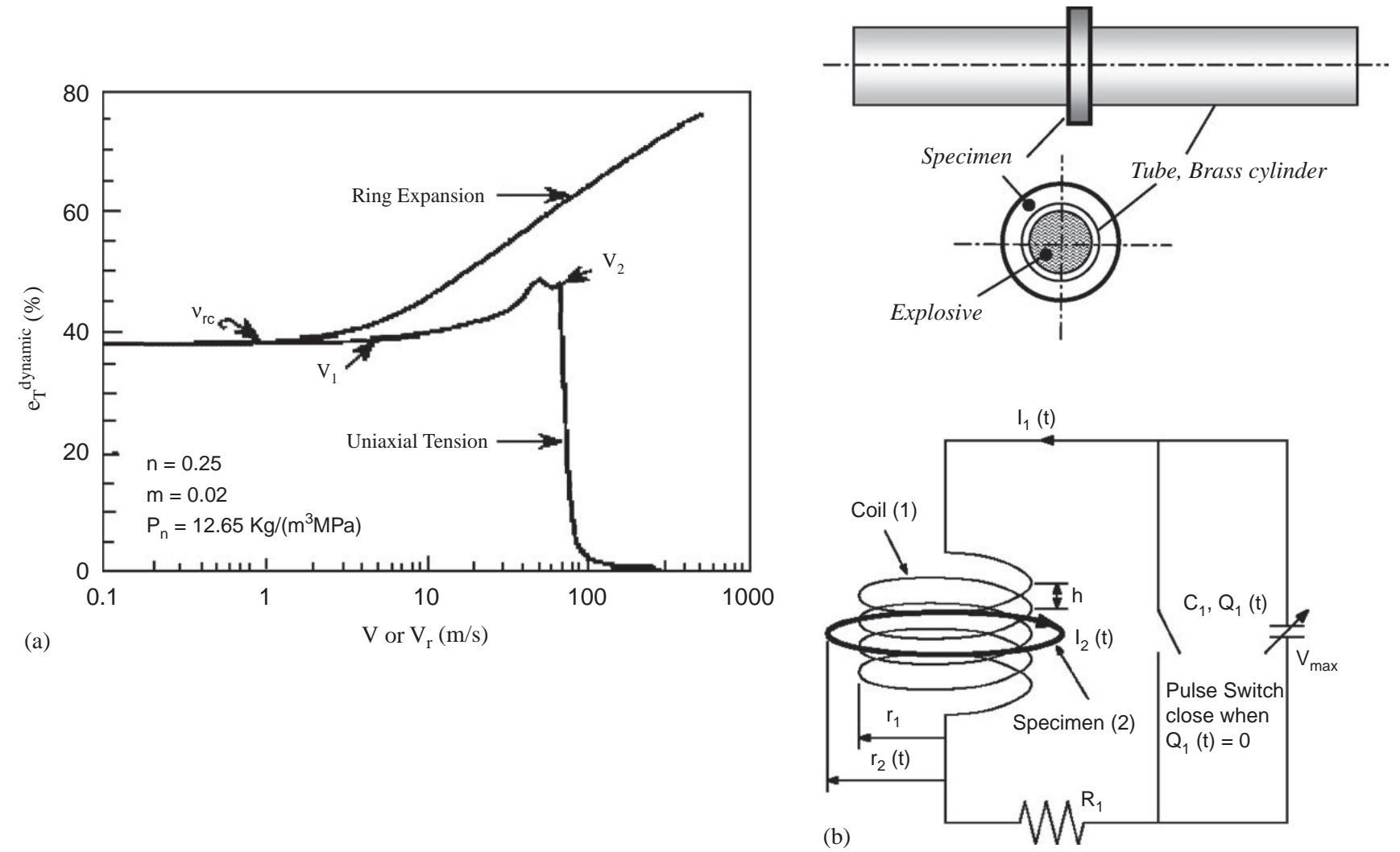

Fig. 1. (a) Evolution of the failure strain in dynamic loading, comparison between dynamic tensile test and ring expansion [1] and (b) configuration of the loading conditions by explosive or by magnetic field in the ring expansion test $[2,3]$.

high ductility observed during ring expansion being generally related to inertial effects $[1,4]$. The experiment consists of loading a ring of radius $R$ at a roughly constant velocity $V_{0}$ which varies from 50 to $300 \mathrm{~m} / \mathrm{s}$. The dynamic loading is procured by a magnetic field or by the use of explosives (Fig. 1b), the former providing a more uniform impact velocity $V_{0}$ in time. Several experimental set-ups have been proposed for these tests, the first one by Niordson in 1965 [5]. Currently, the materials used in the experimental tests are aluminium [4,6,7] or copper [6], and typical values of the strain rate reached during the experiments are within the range $10^{3} \leqslant \dot{\varepsilon} \leqslant 10^{4} \mathrm{~s}^{1}$. As stated above, the expansion process is used to determine the dynamic behaviour of the material and specifically the number of fragments and the failure mode which appear at very high expansion rates. After testing the ring, the fragments were recovered, counted and examined to establish the effect of applied velocity $V_{0}$ on the number of fragments.

Physical phenomena occuring during the test are complex, and the resulting fragmentation pattern is the consequence of the competition between failure modes related to dynamic loading such as shear banding, and those characteristic of static loading such as void growth, fracture nucleation and necking. In addition, during the impulsive loading, elastic and plastic waves strongly interact with necking and fracture processes, so numerical simulation of the expansion process would provide valuable complementary information about the experimental procedure and a precise prediction of the number of fragments in terms of imposed radial velocities and strain rates $\dot{\varepsilon}_{0}=V_{0} / R$. A $3 \mathrm{D}$ Finite Element simulation was used for the analysis of dynamically loaded rings, focusing on mild steels since few results were available for this type of ductile material ( $\left.\varepsilon_{\text {failure }}^{\text {stati }} \approx 30 \%[8]\right)$. A precise constitutive relation [9] covering hardening, strain rate and temperature sensitivity, validated for several strain rates and temperatures [8], was coupled to the commercial FE code ABAQUS/Explicit through an original thermoviscoplastic algorithm proposed in [10]. A parametric study is also given to analyse the effect of the hardening exponent on the number of fragments. The FE model is compared with an analytical model proposed in [11], which uses a linear perturbation technique to capture the dynamic necking, and that of a numerical approach which considers elements with a cohesive law to predict 
the failure of the ring [7]. The effect of the strain hardening exponent on the failure mode was also investigated in view of the fact that, with low strain hardening, the Critical Impact Velocity (CIV) appears to change radically the shape of the fragments, as was also observed in the perforation test [12].

\section{Constitutive relation}

To simulate the process of ring expansion, a reference material with well-known mechanical behaviour was used: a mild steel ES, commonly used in the automotive industry. With an average grain size $\phi \approx 16 \mu \mathrm{m}$, it is isotropic and shows strain rate and temperature sensitivity. The chemical composition is given in Table 1.

A number of tensile, double shear and perforation tests have been performed during the last decade to characterise this material, with special attention to the precise reciprocity effects between the strain rate and temperature $T$, the quantities defining the process of thermal activation [12,13], with tests over a broad range of $\dot{\varepsilon}$ and $T$. The original constitutive relation applied in this paper is based in part on the theory of dislocations [13], the evolution of microstructure being taken into account by one or two internal state variables $s_{j}$ (density of dislocation and density of mobile dislocation), leading to a hardening relation which, in a general simplified form, may be written as

$$
\sigma=g\left[\bar{\varepsilon}^{\mathrm{p}}\left(s_{j}\right), \dot{\bar{\varepsilon}}^{\mathrm{p}}, T, s_{j}, h\left(\dot{\bar{\varepsilon}}^{\mathrm{p}}, T\right)\right],
$$

where $T$ is the absolute temperature and $\bar{\varepsilon}^{\mathrm{p}}$ the equivalent plastic strain. However, such a formulation is too complicated to be implemented directly into FE codes, mainly due to the complexity of each equation, and the difficulty of incorporating the large number of physical constants (around 20) to be determined, whereas phenomenological approaches are better adapted to numerical analyses. To reduce the number of constants and to facilitate the utilisation in a FE code, a semi phenomenological approach was proposed in $[8,9,12]$. This set of constitutive relations encompasses strain hardening and strain rate and temperature sensitivity through a lower number of constants, limited to eight, and this model with fewer constants allows to cover the same tendencies as those predicted by the physical approach. In this formulation the stress of plastic flow is presented in an additive form:

$$
\sigma\left(\bar{\varepsilon}^{\mathrm{p}}, \dot{\bar{\varepsilon}}^{\mathrm{p}}, T\right)=\frac{E(T)}{E_{0}}\left[\sigma_{\mu}\left(\overline{\bar{\varepsilon}}^{\mathrm{p}}, \dot{\bar{\varepsilon}}^{\mathrm{p}}, T\right)+\sigma *\left(\dot{\bar{\varepsilon}}^{\mathrm{p}}, T\right)\right],
$$

where $\sigma_{\mu}$ and $\sigma^{*}$ are, respectively, the internal and the effective stress component. The first term is directly related to the strain hardening of the material and the second defines the contribution of thermal activation (combination of temperature and strain rate). $E(T)$ is of the Young's modulus as a function of temperature; this expression is based to some extent on physical considerations:

$$
E(T)=E_{0}\left\{1-\frac{T}{T_{\mathrm{m}}} \exp \left[\theta^{*}\left(1-\frac{T_{\mathrm{m}}}{T}\right)\right]\right\},
$$

where $E_{0}$ is the Young's modulus at $T=0 \mathrm{~K}, \theta^{*}$ is constant of the material and $T_{\mathrm{m}}$ is the melting temperature.

The explicit form proposed to define the two stress components is inspired by the physical approach [13 15$]$ via the theory of thermal activation. The components are given by the following expressions:

$$
\begin{aligned}
& \sigma_{\mu}=B\left(\dot{\bar{\varepsilon}}^{\mathrm{p}}, T\right)\left(\varepsilon_{0}+\bar{\varepsilon}^{\mathrm{p}}\right)^{n\left(\dot{\bar{\varepsilon}}^{\mathrm{p}}, T\right)}, \\
& \sigma^{*}=\sigma_{0}^{*}\left\langle 1-D_{1}\left(\frac{T}{T_{\mathrm{m}}}\right) \log \left(\frac{\dot{\varepsilon}_{\max }}{\dot{\bar{\varepsilon}}^{\mathrm{p}}}\right)\right\rangle^{m^{*}},
\end{aligned}
$$

\begin{tabular}{|c|c|c|c|c|c|c|c|c|c|c|}
\hline $\mathrm{Mn}$ & $\mathrm{Al}$ & $\mathrm{Cr}$ & $\mathrm{C}$ & $\mathrm{Ni}$ & $\mathrm{S}$ & $\mathrm{Cu}$ & $\mathrm{Si}$ & $\mathrm{P}$ & $\mathrm{N}$ & $\mathrm{Ti}$ \\
\hline $0.203 \%$ & $0.054 \%$ & $0.041 \%$ & $0.03 \%$ & $0.018 \%$ & $0.011 \%$ & $0.009 \%$ & $0.009 \%$ & $0.008 \%$ & $0.0063 \%$ & $0.002 \%$ \\
\hline
\end{tabular}

Table 1

Chemical composition of mild steel ES 
where $\varepsilon_{0}$ is the strain characterising the yield stress, $B(\dot{\varepsilon}, T)$ and $n(\dot{\varepsilon}, T)$ are respectively the modulus of plasticity and the strain hardening exponent, $\dot{\varepsilon}_{\mathrm{c}}$ is the critical strain rate, experimentally obtained and typically very low, $m^{*}$ is the coefficient that characterises the temperature and strain rate sensitivity, $D_{1}$ is the material constant, $\sigma_{0}^{*}$ is the effective stress at $T=0 \mathrm{~K}$ and $\dot{\varepsilon}^{\max }$ is the maximum strain rate limiting the validity of the model. $\langle\bullet\rangle$ is the MacCauley brackets, $\langle\bullet\rangle=0$ if $\bullet\langle 0$ in other cases $\langle\bullet\rangle=\bullet$.

The temperature increase due to adiabatic heating is defined by the following relation:

$$
T\left(\bar{\varepsilon}^{\mathrm{p}}\right)=T_{0}+\frac{\beta}{\rho C_{\mathrm{p}}} \int_{\varepsilon_{\mathrm{e}}}^{\varepsilon_{\max }} \sigma \mathrm{d} \bar{\varepsilon}^{\mathrm{p}},
$$

where $T_{0}$ is the initial temperature, $\rho$ is the density of material, $C_{p}$ is the specific heat at constant pressure assumed constant during numerical simulation and $\beta$ is the Quinney Taylor coefficient which defines the ratio of the plastic work transformed into heat. Although this coefficient varies with the plastic deformation [16,17], a constant value, equal to $\beta=0.9$, is assumed. The effect of temperature is precisely considered in this hardening equation through a number of terms. This is of great importance, notably when high strain rates arise in the material. In this kind of problem, adiabatic heating causes a large temperature increase that changes the elastic and plastic wave speeds, both properties being related to the Young's Modulus and to the strain hardening. The temperature rise slows the propagation of the two waves, inducing, at large strain rates, a trapping of the plastic wave and a localisation of deformation. Hence, the decrease of the Young's Modulus with temperature (Fig. 2a) is considered in the constitutive model through Eq. (3) and both the hardening exponent and the modulus of plasticity in the internal stress account for thermal (and strain rate) effects throughout the following expressions:

$$
\begin{aligned}
& n\left(\dot{\bar{\varepsilon}}^{\mathrm{p}}, T\right)=n_{0}\left\langle 1-D_{2}\left(\frac{T}{T_{\mathrm{m}}}\right) \log \left(\frac{\dot{\bar{\varepsilon}}^{\mathrm{p}}}{\dot{\bar{\varepsilon}}_{\min }}\right)\right\rangle, \\
& B\left(\dot{\bar{\varepsilon}}^{\mathrm{p}}, T\right)=B_{0}\left\langle\frac{T}{T_{\mathrm{m}}} \log \left(\frac{\dot{\varepsilon}_{\max }}{\dot{\bar{\varepsilon}}^{\mathrm{p}}}\right)\right\rangle^{v},
\end{aligned}
$$

where $n_{0}$ is the strain hardening exponent at $T=0 \mathrm{~K}, D_{2}$ is a constant, $\dot{\varepsilon}_{\min }$ and $\dot{\varepsilon}_{\max }$ are the minimum and maximum strain rates assumed in the model, $B_{0}$ is a constant and $v$ is the temperature sensitivity. The restriction imposed on the hardening exponent $(n \geqslant 0)$ to avoid negative values at high strain rates permits to expose the plastic behaviour which appears during plastic deformation caused by the competition between thermal softening and strain hardening (Fig. 2b).
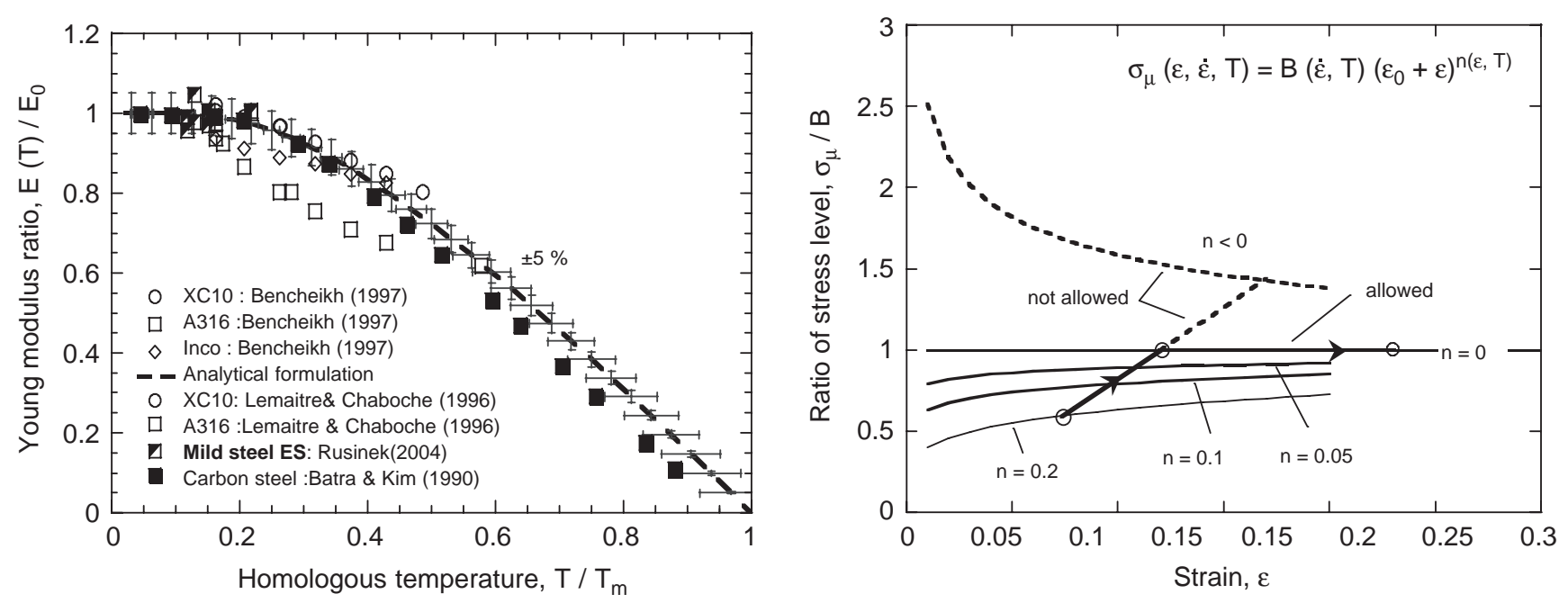

Fig. 2. (a) Evolution of the elastic property with temperature allowing a prediction of thermal softening during high strain rate by adiabatic heating and (b) intensity of the hardening exponent reached during plastic deformation. 
The transition from isothermal to adiabatic conditions for the ES mild steel was found experimentally at a strain rate $\dot{\varepsilon}_{\mathrm{p}}^{\text {transition }}=10 \mathrm{~s}^{1}$. This transition initiates the thermal softening phenomenon and reduces the strain hardening exponent $n=\partial \log \sigma /\left.\partial \log \bar{\varepsilon}^{\mathrm{p}}\right|_{\overline{\dot{\varepsilon}} \mathrm{p}}$. The analytical results, in the form of $\sigma\left(\bar{\varepsilon}^{\mathrm{p}}\right)$ curves obtained by the constitutive relation, are shown in Fig. 3 for different initial values of $n_{0}$.

The effective stress $\sigma^{*}$, which defines the thermally activated component of the stress, is also strongly affected by temperature (and strain rate). With the proposed hardening relation it is possible to define the high strain rate sensitivity commonly observed during experimental characterisation of mild steel ES at strain rates higher than $100 \mathrm{~s}^{1}$ (Fig. 4).

As stated above, adiabatic heating plays an important role during dynamic loading, frequently triggering plastic instabilities. But it also influences the mechanical behaviour of the material if the strain rate is not constant during the loading process, a situation that appears in high-speed cutting or crashworthiness applications. The proposed hardening equation accounts for this effect. As Fig. 5 shows, the adiabatic heating induces a decrease of the strain hardening, whereas in the isothermal approach the hardening continues to increase with plastic deformation (Fig. 5a). This difference is more patent if a delay appears at the onset of dynamic loading: above a pre-plastic deformation of $\bar{\varepsilon}^{\mathrm{p}}=0.1$, a jump in the strain rate is followed by a stress increase beyond the curve corresponding to the purely adiabatic condition. Hence non-isothermal heating reduces both stress level and rate of strain hardening.

Having shown the ability of the model to reproduce the behaviour of the material under adiabatic conditions, it is interesting to highlight its capability to fit experimental data over a broad range of strain rates. Fig. 6 shows how the strain rate sensitivity is well defined in a range of strain rates from $10^{4}$ to $10^{3} \mathrm{~s}{ }^{1}$ and covering both isothermal and adiabatic conditions. The hardening equation also shows a high strain rate sensitivity at strain rates above $\overline{\bar{\varepsilon}}^{\mathrm{p}}>10^{4} \mathrm{~s}{ }^{1}$, which is in agreement with the current experimental observations for mild steels [10]. Thus, the constitutive relation allows a study of a number of dynamic load processes such as perforation, shear, tension or crash box test. The model is suitable for metals with BCC structure, which show an additive dependence on the flow stress. It also accounts for the large strain rate sensitivity observed in BCC metals at very high strain rates, much higher than that of FCC metals exhibiting a lower movement of screw dislocations. In addition, a complete optimisation algorithm has been developed to determine the

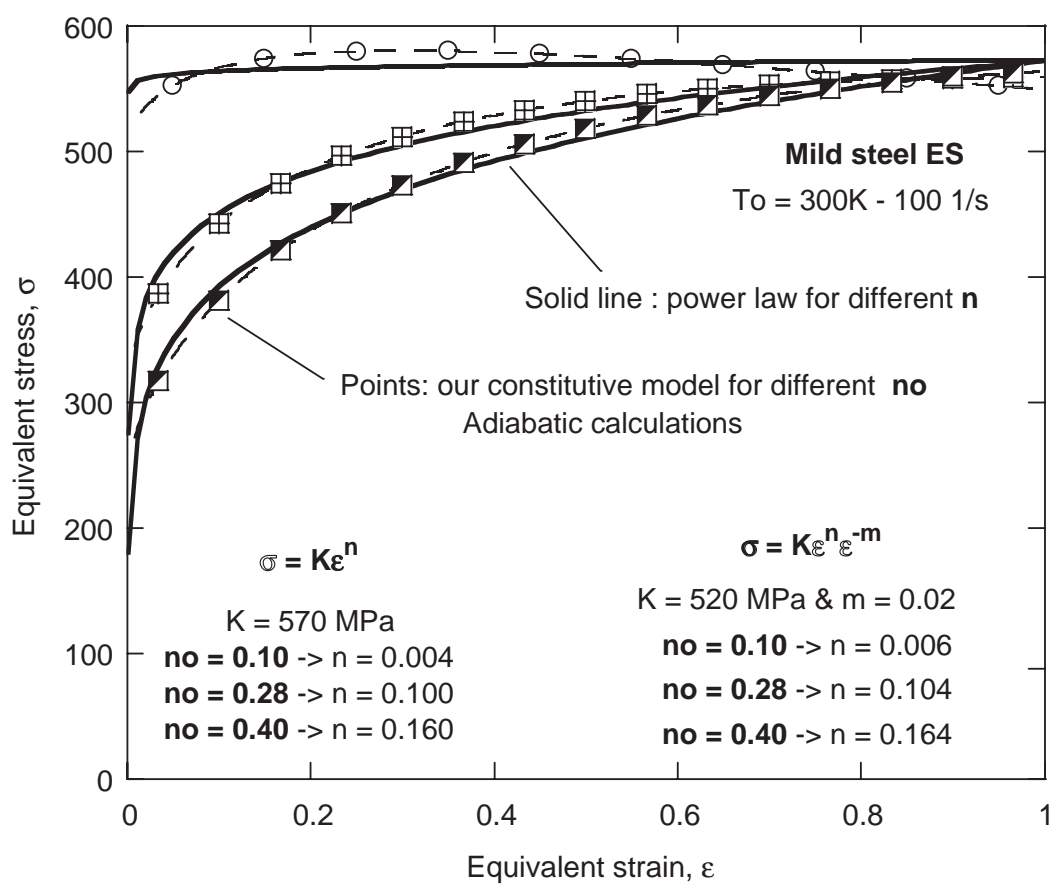

Fig. 3. Equivalence of the hardening coefficient used in the constitutive relation and the hardening coefficient currently used for a power law. 


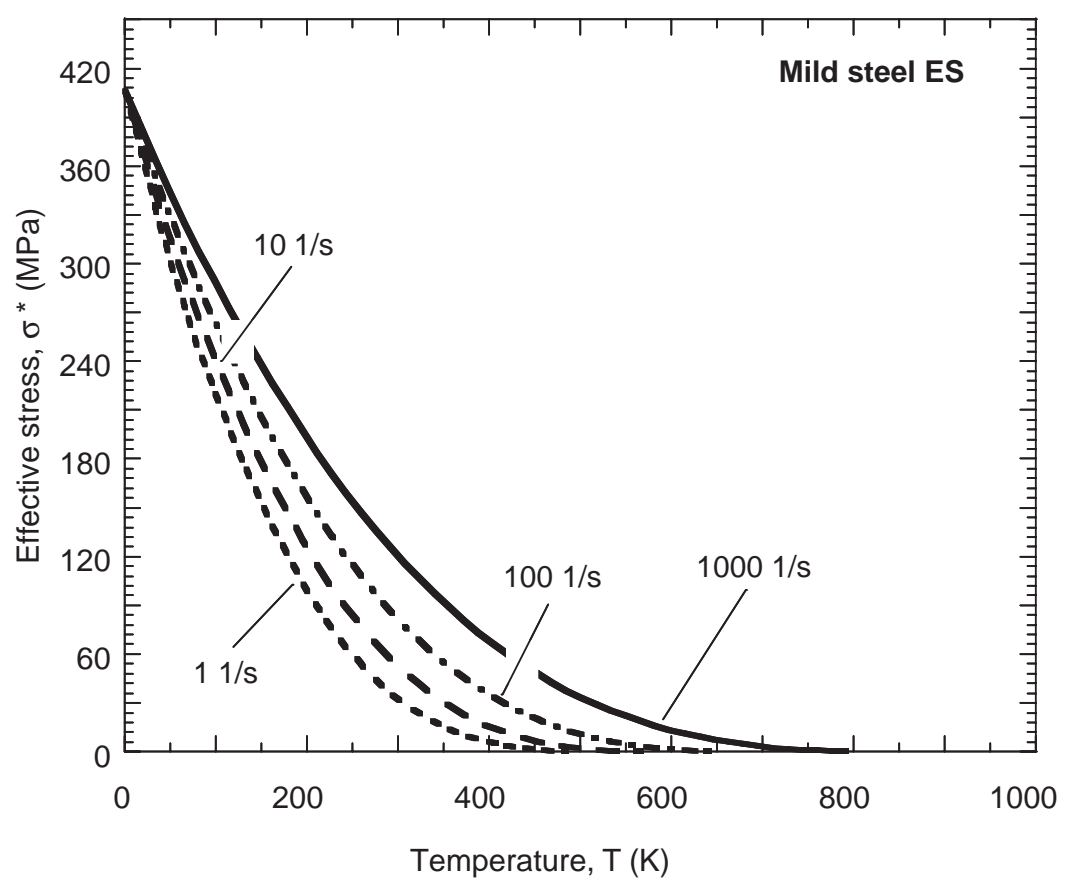

Fig. 4. Analytical prediction of the effect of strain rate on the effective stress.
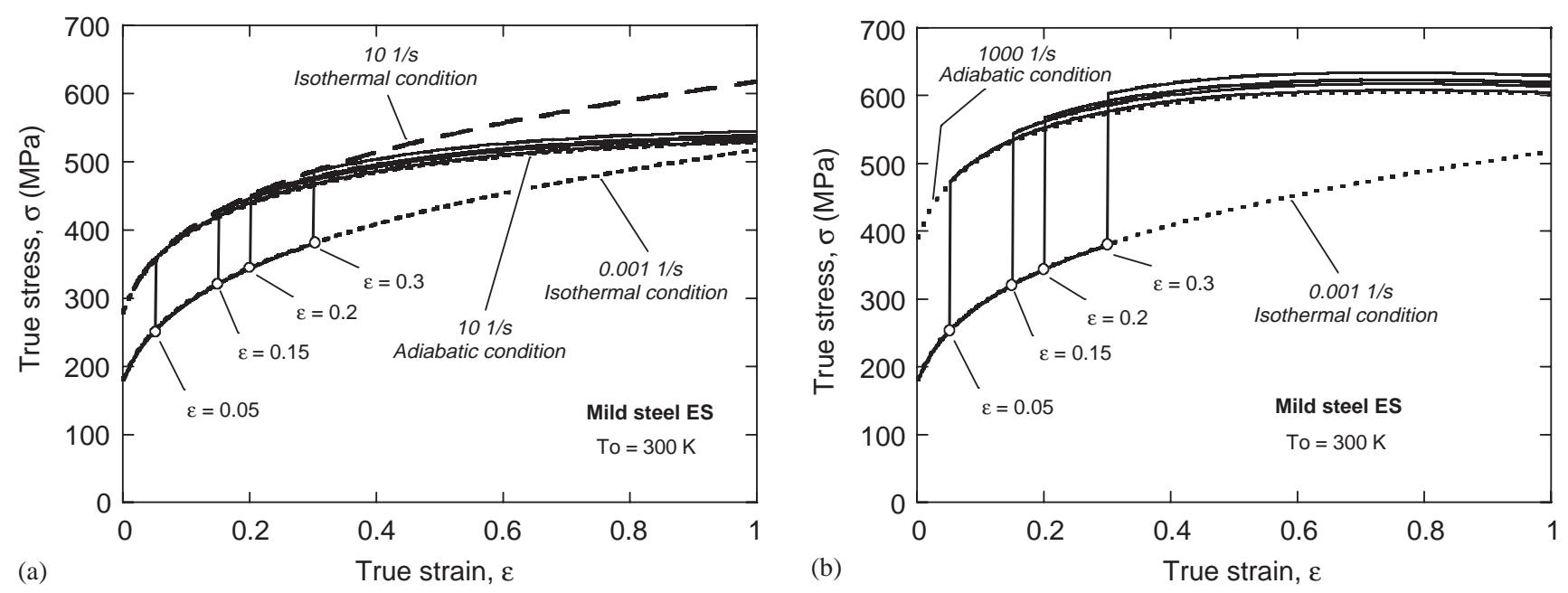

Fig. 5. Effect of adiabatic heating at high strain rates for different pre plastic deformation. Curves obtained from the hardening equation: (a) from quasi static and isothermal conditions (from $10^{-3} \mathrm{~s}^{-1}$ ) to adiabatic conditions $\left(10 \mathrm{~s}^{-1}\right)$ and (b) from quasi static and isothermal conditions $\left(10^{-3} \mathrm{~s}^{-1}\right)$ to adiabatic conditions $\left(10^{3} \mathrm{~s}^{-1}\right)$.

unique optimal set of constants for each material [12]. To use the constitutive relation coupled to a simulation tool, the following integration scheme was adopted.

\subsection{Implicit integration algorithm}

The relations presented, together with constitutive equations following the classical isotropic $J_{2}$ hypoelastic-plastic theory, should be integrated through a stress update algorithm. To integrate the rate equations into a large deformation finite element code, incremental objectivity is achieved by rewriting them in a neutralised or corrotational configuration [18]. Thus, the complicated objective stress rate present in the 


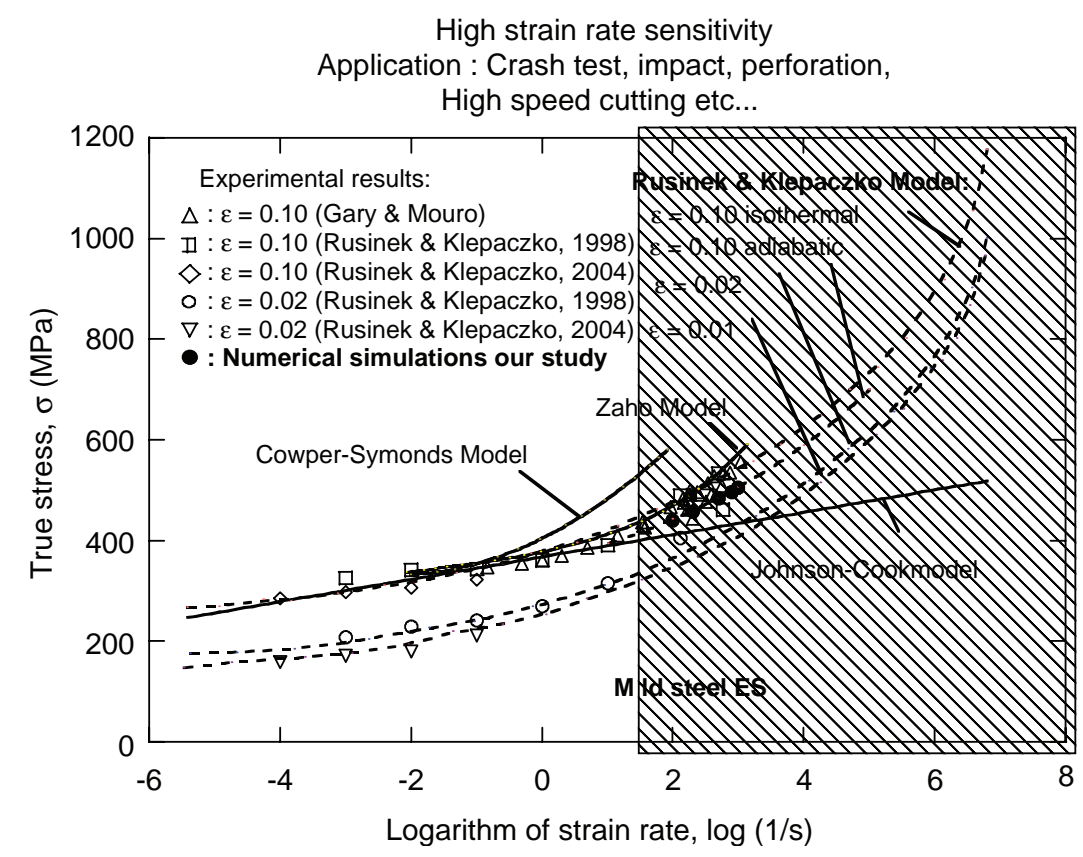

Fig. 6. Analytical prediction of the model for mild steel ES, comparison with several constitutive relations and experimental results.

elastic behaviour law can be computed as a simple time derivative. The rate equations defined above are form-identical in the neutral configuration and a small deformation formulation could be used. To solve this system of incremental equations, we used the algorithm proposed in [10]. Now follows a brief description of the constitutive equations and of the algorithm within the frame of the neutralised configuration.

The yield condition is defined as follows:

$$
f\left(\sigma_{i j}, \bar{\varepsilon}^{\mathrm{p}}, \dot{\bar{\varepsilon}}^{\mathrm{p}}, T\right)=\bar{\sigma}-\sigma_{y}\left(\bar{\varepsilon}^{\mathrm{p}}, \dot{\bar{\varepsilon}}^{\mathrm{p}}, T\right)=0,
$$

where $\bar{\sigma}$ is the equivalent stress, $\sigma_{\mathrm{y}}$ is the yield stress defined by the constitutive equation previously described, $\bar{\varepsilon}^{\mathrm{p}}$ is the equivalent plastic strain and $\dot{\bar{\varepsilon}}^{\mathrm{p}}$ is the equivalent plastic strain rate:

$$
\begin{aligned}
& \dot{\bar{\varepsilon}}^{\mathrm{p}}=\sqrt{\frac{2}{3} \dot{\varepsilon}_{i j}^{\mathrm{p}}: \dot{\varepsilon}_{i j}^{\mathrm{p}},} \\
& \overline{\bar{\varepsilon}}^{\mathrm{p}}=\int \dot{\bar{\varepsilon}}^{\mathrm{p}} \mathrm{d} t .
\end{aligned}
$$

Assuming additive decomposition of the deformation tensor (hypoelastic approach) the tensor of total strain rate $\dot{\varepsilon}_{i j}$ is written as a sum of the elastic strain rate tensor $\dot{\varepsilon}_{i j}^{\mathrm{e}}$, the plastic strain rate tensor $\dot{\varepsilon}_{i j}^{\mathrm{p}}$ and the thermal strain rate tensor $\dot{\varepsilon}_{i j}^{\mathrm{T}}$. Elastic strains are related to stress through an isotropic hypoelastic law:

$$
\dot{\sigma}_{i j}=C_{i j k l} \dot{\varepsilon}_{k l}^{\mathrm{e}} \text {, }
$$

where $C_{i j k l}$ is the stiffness tensor.

The thermal strains tensor is defined as follows:

$$
\dot{\varepsilon}_{i j}^{\mathrm{T}}=\alpha \dot{T} \delta_{i j}
$$

where $\alpha$ is the coefficient of thermal expansion and $\delta_{i j}$ is the unit matrix $\left(\delta_{i j}=1\right.$ if $\left.i=j\right)$

To define the plastic flow, the normality rule is used which relates plastic strain rate $\dot{\varepsilon}_{i j}^{\mathrm{p}}$ to the stress after

$$
\dot{\varepsilon}_{i j}^{\mathrm{p}}=\dot{\lambda} \frac{\partial f}{\partial \sigma_{i j}},
$$


where $\dot{\lambda}$ is the rate plastic multiplier [42]. In addition, considering adiabatic heating, the temperature rate is defined by the following relation:

$$
\dot{T}=\frac{\beta}{\rho C_{\mathrm{p}}} \sigma_{i j} \dot{\mathrm{\varepsilon}}_{i j}^{\mathrm{p}} \text {. }
$$

In the standard Perzyna overstress models [19], the consistency condition is not used, and excursions of stress outside the yield surface are allowed [43]. Wang et al. [20] proposed the so-called "consistency viscoplasticity models" to include rate effects in the consistency condition. In the proposed algorithm, the consistency model is extended to integrate the thermoviscoplastic rate equations, via the equality of equivalent stress and yield stress for updated values of plastic strain, plastic strain rate and temperature. In the frame of the return-mapping algorithms, the consistency condition, Eq. (9), could be written in terms of the equivalent plastic strain increment corresponding to a time step:

$$
f\left(\Delta \bar{\varepsilon}^{\mathrm{p}}\right)=0 .
$$

Linearising the consistency condition, the following equation is found which allows us to iteratively obtain $\Delta \bar{\varepsilon}^{\mathrm{p}}$ by iteration:

$$
f_{(k+1)} \approx f_{(k)}+\frac{\partial f}{\partial \sigma_{i j}}\left(-\left.\delta \varepsilon_{(k)}^{\mathrm{p}} 2 G \frac{\partial f}{\partial \sigma_{i j}}\right|_{(k)}\right)+\left.\frac{\partial f}{\partial \varepsilon^{\mathrm{p}}}\right|_{(k)} \delta \varepsilon_{(k)}^{\mathrm{p}}+\left.\frac{\partial f}{\partial \dot{\varepsilon} \mathrm{p}}\right|_{(k)} \frac{\delta \varepsilon_{(k)}^{\mathrm{p}}}{\Delta t}+\left.\frac{\partial f}{\partial T}\right|_{(k)} \frac{\beta}{\rho C_{p}}\left(\delta \varepsilon_{(k)}^{\mathrm{p}} \sigma_{n+1}^{\text {trial }}-6 G \Delta \varepsilon_{(k)}^{\mathrm{p}} \delta \varepsilon_{(k)}^{\mathrm{p}}\right)=0
$$

where $k$ is an iterative index. Solving this equation leads to a generalisation of the well-known radial return method

$$
\delta \bar{\varepsilon}_{(k)}^{\mathrm{p}}=\frac{f_{(k)}}{3 G-\left.\frac{\partial f}{\partial \bar{\varepsilon}^{\mathrm{p}}}\right|_{(k)}-\left.\frac{1}{\Delta t} \frac{\partial f}{\partial \overline{\bar{c}}^{\mathrm{p}}}\right|_{(k)}-\left.\frac{\partial f}{\partial T}\right|_{(k)} \frac{\beta}{\rho C_{p}}\left(\bar{\sigma}_{n+1}^{\text {trial }}-6 G \Delta \bar{\varepsilon}_{(k)}^{\mathrm{p}}\right)}
$$

The derivatives of the yield function in terms of $\bar{\varepsilon}^{\mathrm{p}}, \dot{\bar{\varepsilon}}^{\mathrm{p}}$ and $T$ are easily obtained for the proposed hardening model, since no discontinuities are present in the ranges $\dot{\varepsilon}_{\min }<\dot{\bar{\varepsilon}}^{\mathrm{p}}<\dot{\varepsilon}_{\max }$ and $0<T<T_{\mathrm{m}}$ [21].

\subsection{Analysis of ring expansion by simulation and analytical approach}

The numerical analysis was performed using the Finite Element commercial code ABAQUS/Explicit. An initial mesh with 300 8-node trilinear reduced integration brick elements including hourglass control (C3D8R in ABAQUS notation [22]) was used to confirm the validity of both the constitutive relation and the algorithm to simulate the expansion of a ring at very high velocities $1 \leqslant V_{0} \leqslant 500 \mathrm{~m} / \mathrm{s}$ and room initial temperature. The inner radius of the ring is equal to $R_{0}=16 \mathrm{~mm}$, with a thickness of $t=1 \mathrm{~mm}$ and a width of $l=1 \mathrm{~mm}\left(1 \mathrm{~mm}^{2}\right.$ square cross section), Fig. 7. Later on, we present a study of the influence of the mesh and of the ring dimensions. The boundary condition is an imposed radial velocity $V_{0}$ constant through time.

Propagation and rarefaction of the waves along the specimen causes a loss of deformation homogeneity and the onset of a first neck. This induces a lack of radial symmetry and the development of secondary necks. No geometrical or material imperfections were introduced [23] in the model since they could change the necking problem [24,25], the numerical uncertainties through the integration process being enough to trigger instability, as discussed below. The same approach no artificial imperfections used by the authors to analyse the deformation localisation in dynamic tensile testing $[8,26]$, revealed a change in the necking position with the impact velocity and a localisation close to the impact side for pulling velocities beyond $100 \mathrm{~m} / \mathrm{s}$ due to trapping of the plastic wave. Other workers had observed the same effect in rod or sheet steel specimens [27-30,45].

To arrive at a division of the ring through the development of fragments after necking initiation, it is necessary to consider a failure criterion. In dynamic tensile tests the failure strain of the specimen depends very much on the loading velocity, as was observed experimentally by Wood [31] and confirmed by the present authors with the numerical approach used in this work [8]. As shown in Fig. 8a, a sudden decrease of the failure strain appears in tensile conditions above the CIV. This could be defined as the pulling velocity which 


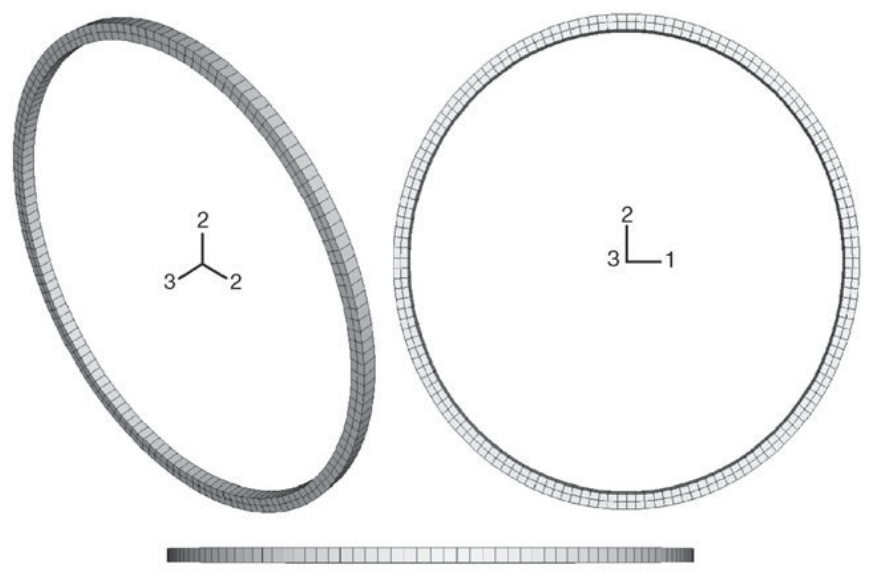

- Inner Radius (RO): $16 \mathrm{~mm}$, Outer Radius (RI): $17 \mathrm{~mm}$

- Thickness $(t): 1 \mathrm{~mm}$, Width: $1 \mathrm{~mm}$

Fig. 7. Definition of reference geometry and mesh used during numerical simulations of ring expansion.
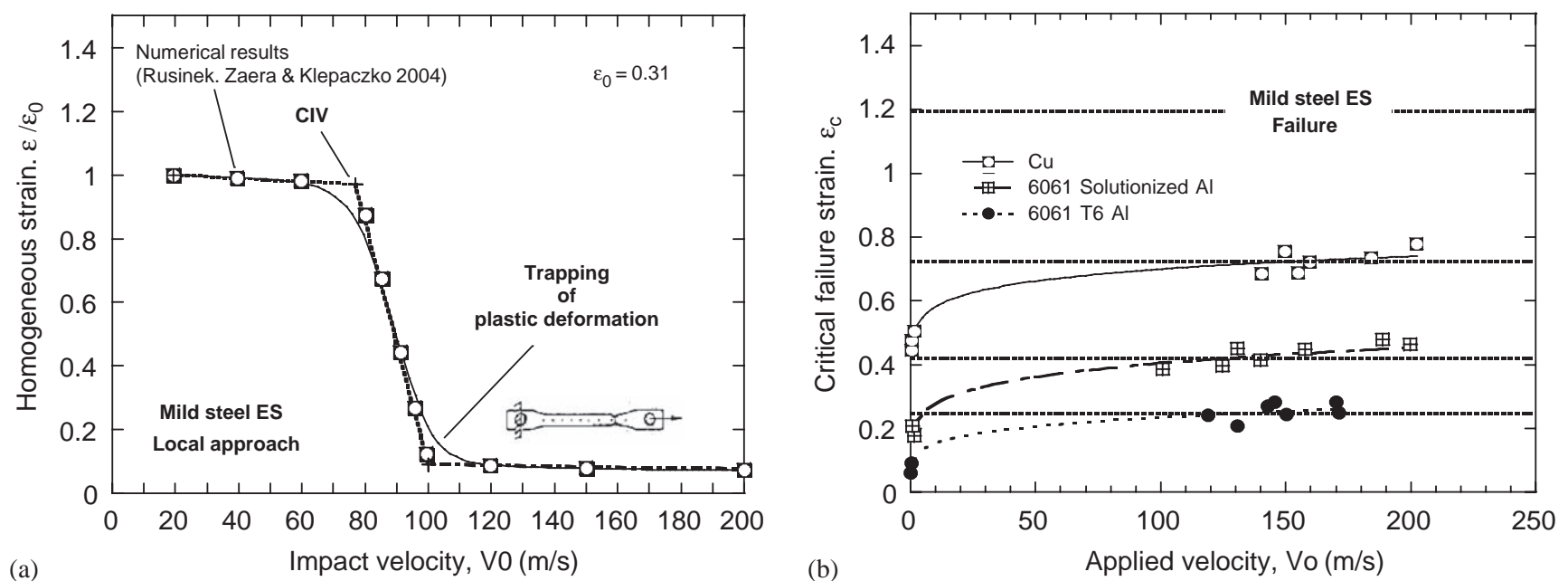

Fig. 8. (a) Determination of the CIV in a mild steel ES [8,12] and (b) definition of the critical failure strain in expansion based on the CIV [5].

leads to the trapping of the plastic wave, which induces an instantaneous failure of the specimen close to the loaded end. The CIV effect, which is related to wave propagation [31], is more significant in materials presenting little hardening.

On the contrary, the failure strain evolution of a ring expanding at very high strain rate is completely different to that of a tensile test. Fig. 8b shows, for different materials considered for ring expansion testing, the values of strain at failure $\varepsilon_{\mathrm{c}}$ as a function of the applied velocity. The critical strain continuously increases and rapidly reaches a plateau. So, a constant value of $\varepsilon_{\mathrm{c}}$ has been adopted to define the failure of the material in the simulations performed in this analysis.

To determine the value of the strain at failure $\varepsilon_{\mathrm{c}}$, which should be higher in ring expansion than in a tensile test, the previous constitutive relation Eqs. (2)-(8) were used. It allows a calculation not only of the strain level which defines complete failure:

$$
\frac{\partial \sigma}{\partial \varepsilon}=0 \quad\left(\varepsilon_{\mathrm{c}}, \text { failure }\right)
$$


but also the strain level corresponding to the loss of homogeneity (Considère criterion [32]):

$$
\frac{\partial \sigma}{\partial \varepsilon}=\sigma \quad\left(\varepsilon_{\text {neck }}, \text { lost of homogeneity }\right)
$$

In ductile materials, such as mild steel (reference hardening exponent $n_{0}=0.28$ ), the failure strain $\varepsilon_{\mathrm{c}}$ is higher than that at the initiation of necking $\varepsilon_{\text {neck }}$ due to the delay caused by the localisation of plastic deformation during loading. This can be observed in Figs. 9a and b, which plot critical strains for different values of strain rate. At $n_{0}=0.28, \varepsilon_{\text {neck }}$ quickly decreases with strain rate, remaining close to 0.1 in adiabatic conditions, see Fig. 9b. Nevertheless, all the analytical predictions of $\varepsilon_{\mathrm{c}}$ in dynamic loading are ten times greater $\varepsilon_{\mathrm{c}}=1$. This value is very high as compared to the failure strain observed in tension, but it is in agreement with the observations of several workers [3,7,33]. For the simulations, an arbitrary value $\varepsilon_{\mathrm{c}}=1.2$ has been used, in agreement with Pandolfi et al. [7] where $1.2 \leqslant \varepsilon_{\mathrm{c}} \leqslant 1.3$. Figs. 9a and $\mathrm{b}$ also show the effect of the hardening exponent on the value of the critical strains; a small hardening $n_{0} \leqslant 0.1$ strongly reduces the failure strain whereas ductility increases with large hardening. The failure criterion used in this work is close to Drucker criterion in $[34,35]$ since the failure appears when $\dot{\sigma} \dot{\varepsilon} \leqslant 0$ (unstable material). Since $\dot{\varepsilon}$ is always positive in the local element, the condition to satisfy the previous condition is necessary to obtain $\dot{\sigma} \leqslant 0$ which corresponds to $\propto \partial \sigma / \partial \varepsilon=0$. A secondary effect of $n_{0}$ on the onset and evolution of the necking process comes through the modification of the plastic wave speed, which is directly connected to the hardening and the
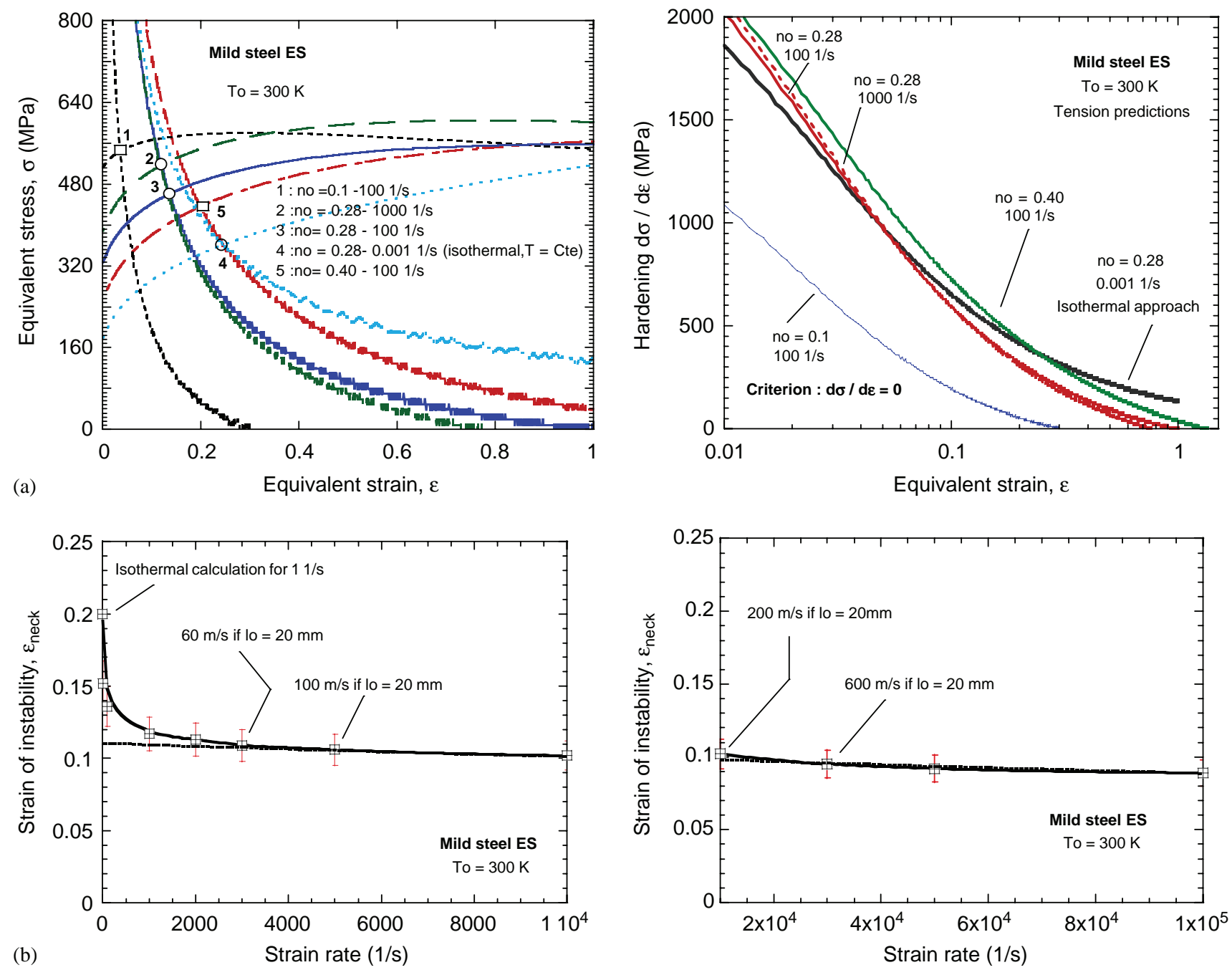

Fig. 9. (a) Definition of the loss of homogeneity during the tensile test; (b) definition of the necking failure strain level, using the Eq (19a); strain of instability $\partial \sigma / \partial \varepsilon \quad \sigma$ in mild steel ES ( $\left.n_{0} \quad 0.28\right)$. 


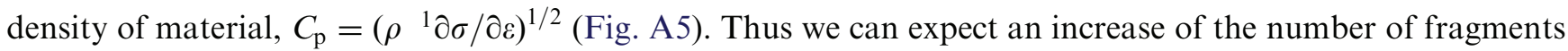
$N$, with a decrease of $n_{0}$ or an increase of $\rho$. This assumption is discussed in the next section.

In ductile materials, the failure criterion here described reproduces the process of necking, depicted in Fig. 10, leading to the element removal when the neck is completely developed. Since $\varepsilon_{\mathrm{c}}$ is fairly high, the growth of each neck after loss of homogeneity remains relatively stable until $\bar{\varepsilon}^{\mathrm{p}} \approx 1$. In brittle materials, several authors $[7,36,37,46]$ used cohesive elements featuring a force-opening curve with a sudden force decrease. This weak behaviour could also be characterised by the proposed failure criterion, using a critical strain $\varepsilon_{\mathrm{c}}$ which decreases as the hardening exponent diminishes. In fact, when the variable time is eliminated from the curves of Fig. 10, the resultant stress strain relation is close to that defined through the cohesive law.

To introduce a dependence of the failure strain $\varepsilon_{\mathrm{c}}$ on the hardening coefficient $n_{0}$, the following relation was proposed:

$$
\varepsilon_{\text {failure }}=\lambda n_{0},
$$

$\lambda$ being a constant close to $\lambda=4$ defined by the reference values $n_{0}=0.28$ and $\varepsilon_{\text {failure }}=1.2$ (Table 2). This approach served to analyse the effect of hardening on the number of fragments. The ratio $\varepsilon_{\mathrm{c}} / n_{0}=4$ is assumed to be constant. A similar value (between 3 and 4) was used by Triantafyllidis and Waldenmyer [3].

Once the failure criterion was defined, the simulation of ring expansion was made using the abovementioned hardening equation to analyse the number of fragments that appear on increasing the imposed radial velocity speed $V_{0}$. This study is compared with the results obtained by other workers from different materials: several experimental data; an analytical approach for 6061 aluminium based on the linear perturbation technique [11] and numerical simulations for 1100 aluminium using cohesive elements [7]. The constitutive relation used in the analytical approach is a power law $\sigma=K \bar{\varepsilon} \mathrm{p}^{n} \overline{\bar{\varepsilon}} \mathrm{p}^{m}$ with no strain rate sensitivity ( $K=183 \mathrm{MPa}, n=0.223$ and $m=5 \times 10^{7}$ corresponding to 6061 aluminium), whereas the one considered in the numerical study (referenced in [38]) is more sophisticated and takes into account strain, strain rate and temperature:

$$
\bar{\sigma}=\sigma_{\mathrm{y}}\left[1-\left(\frac{T-T_{0}}{T_{\mathrm{m}}-T_{0}}\right)^{\alpha}\right]\left(1+\frac{\bar{\varepsilon}^{\mathrm{p}}}{\varepsilon_{0}^{\mathrm{p}}}\right)^{1 / n}\left[1+\left(\frac{\dot{\bar{\varepsilon}} \mathrm{p}}{\dot{\varepsilon}_{0}^{\mathrm{p}}}\right)\right]^{1 / \mathrm{m}} .
$$
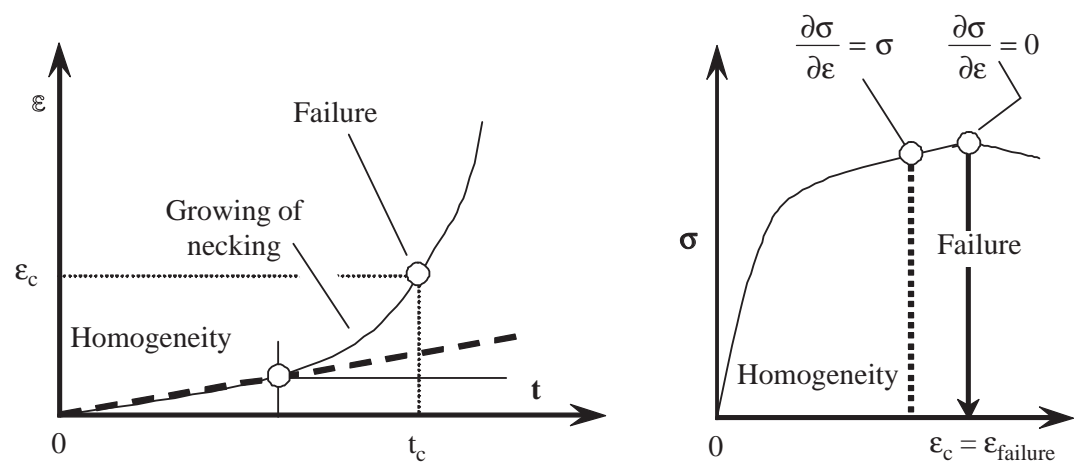

Fig. 10. Definition of the failure criterion used during numerical simulations in terms of strain level and stress.

Table 2

Failure strain used during numerical simulations with different hardening exponents

\begin{tabular}{lll}
\hline$n_{0}$ & $\varepsilon_{\mathrm{c}}$ & $\lambda$ \\
\hline 0.1 & 0.40 & 4 \\
0.28 & 1.20 & 4.28 \\
0.35 & 1.4 & 4 \\
0.4 & 1.6 & 4 \\
\hline
\end{tabular}


Using the parameters given in [7] for a 1100 aluminium, this equation gives a marked strain rate sensitivity at $\dot{\bar{\varepsilon}}^{\mathrm{p}}>1000 \mathrm{~s}^{1}$. The constants of the power law were estimated in aluminium $(K=133.22 \mathrm{MPa}, n=$ 0.038 and $m=0.01$ ) and in mild steel (Fig. 3) for comparison in terms of the hardening exponent value, which is the parameter with most influence on the number of fragments $N$.

The important parameter is also the definition of the behaviour at very high strain rate, i.e. a high stress increase of a strain level imposed (Figs. A2 and A5).

Using the previous experimental results obtained for different kinds of aluminium, it is possible to analyse experimentally some of the effects. In this case, the curve in Fig. 11 shows that at very high imposed velocity, the number of fragments will be higher for a small hardening coefficient. The strain rate transition in these two materials from athermal to thermal activation (described by a quick stress increase) is similar and equal to $\dot{\varepsilon}>1000 \mathrm{~s}^{1}$. This value corresponds to the strain rate reached during ring expansion since $2000 \leqslant \dot{\varepsilon} \leqslant 6250 \mathrm{~s}{ }^{1}$ for the ring radii considered in this work $\left(16 \leqslant R_{0} \leqslant 50 \mathrm{~mm}\right)$. Our numerical simulations studied only the hardening effect, coupled with strain rate sensitivity and adiabatic heating. In brittle failure at high applied velocity, this effect will be lower since the plastic deformation increase in the failure zone will be close to zero.

\subsubsection{Numerical results for the reference geometry and mesh}

The ring geometry, modelled with the mesh shown in Fig. 7, was submitted to radial velocities $V_{0}$ ranging from 1 to $500 \mathrm{~m} / \mathrm{s}$. In order to reach the final number of fragments in each simulation, enough time should be allowed. The inertial effect acting on the initial fragments frequently induces bending, failure, and separation of new pieces, particularly at velocities $V_{0}<10 \mathrm{~m} / \mathrm{s}$. Undoubtedly, these latter fragments are not a consequence of plastic instabilities but they should be considered in the comparison with experimental results. The results of the simulations, some of them depicted in Fig. 12a h, clearly show a marked influence of the imposed velocity on the number of fragments, which increase from one (for the lowest velocity $V_{0}=1 \mathrm{~m} / \mathrm{s}$ ) to more than 30. Plotting $N$ versus $V_{0}$ (Fig. 13) and regarding the evolution of $N$, three regions appear: a first one with a small increase at $1 \leqslant V_{0} \leqslant 100 \mathrm{~m} / \mathrm{s}$, a linear increase at $100 \leqslant V_{0} \leqslant 300 \mathrm{~m} / \mathrm{s}$ and a quick increase at $V_{0}>300 \mathrm{~m} / \mathrm{s}$. Using the same mesh density (two elements through thickness and one element through width) and constitutive equations, the expansion of three additional geometries was also simulated (Table A2) to analyse the geometric effects. Fig. 13 shows that the geometry has little effect.

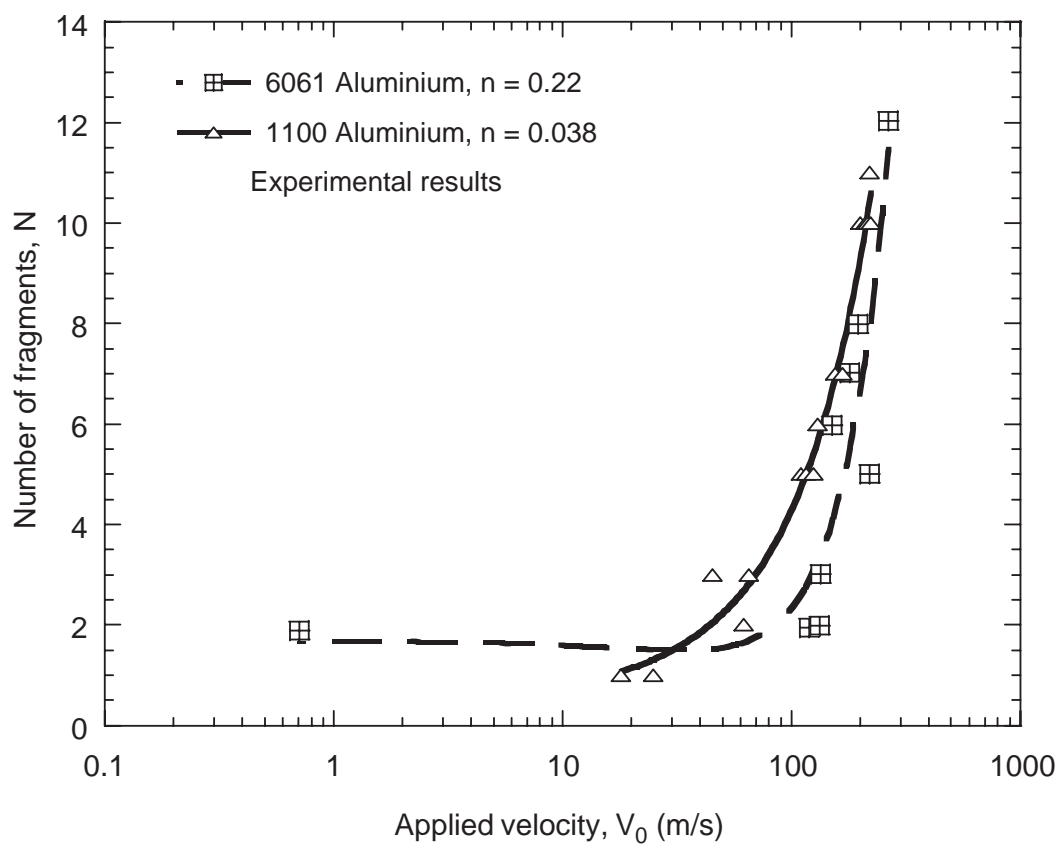

Fig. 11. Effect of the hardening coefficient on the number of fragments in two kinds of aluminium $[4,6,7]$. 


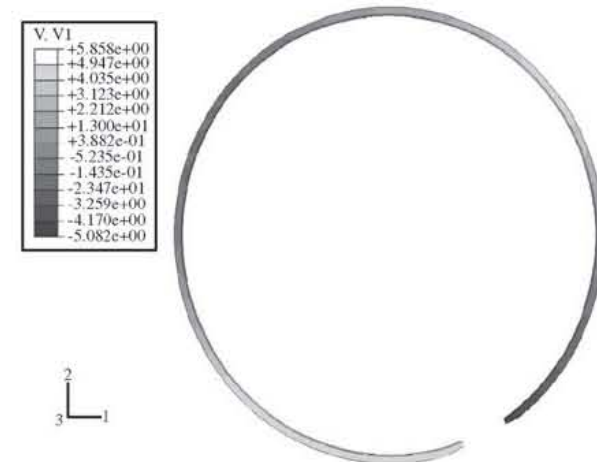

(a)

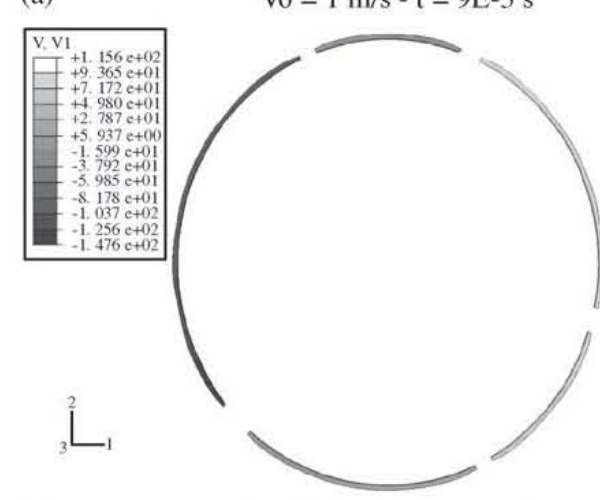

(c)
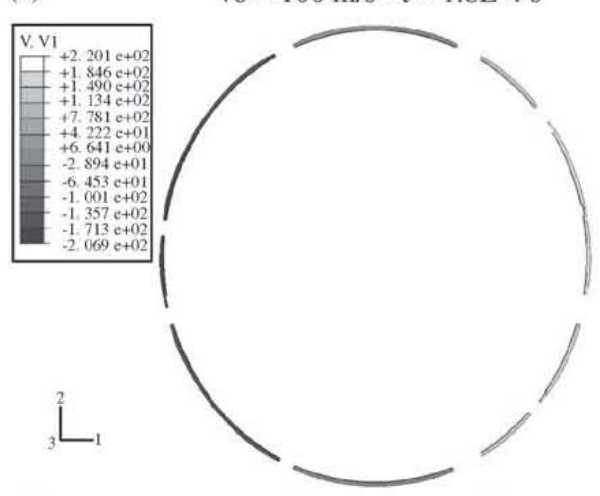

(e)

$\mathrm{V}_{\mathrm{o}}=200 \mathrm{~m} / \mathrm{s}-\mathrm{t}=1.12 \mathrm{E}-4 \mathrm{~s}$
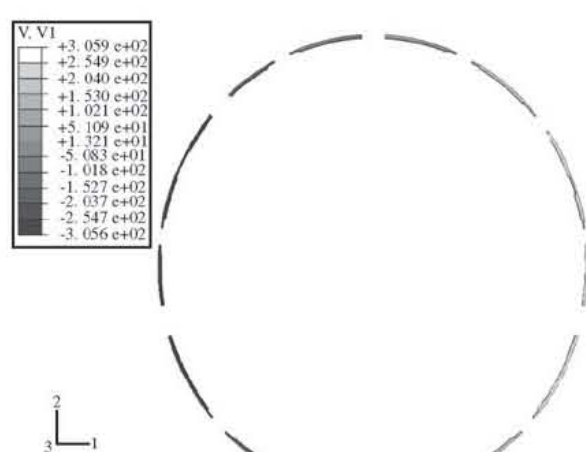

(g)

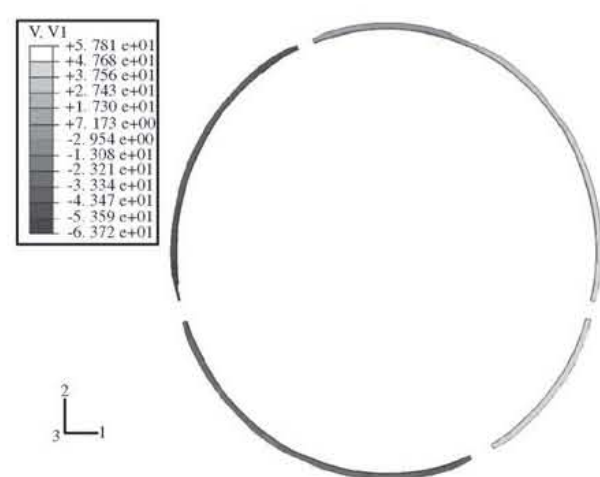

(b)
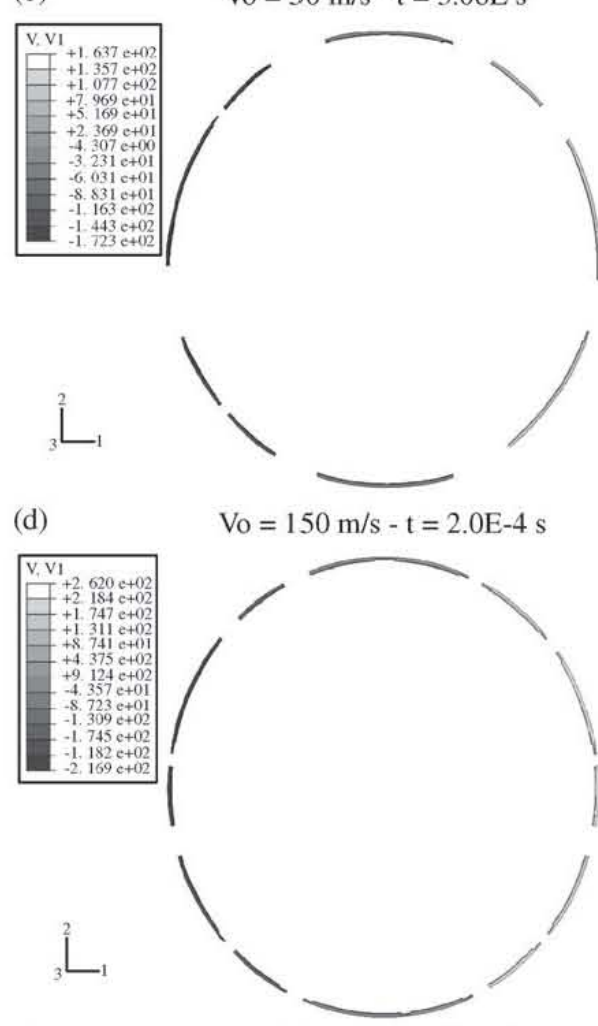

(f)

$\mathrm{V}_{\mathrm{O}}=250 \mathrm{~m} / \mathrm{s}-\mathrm{t}=9.8 \mathrm{E}-5 \mathrm{~s}-$ without necking

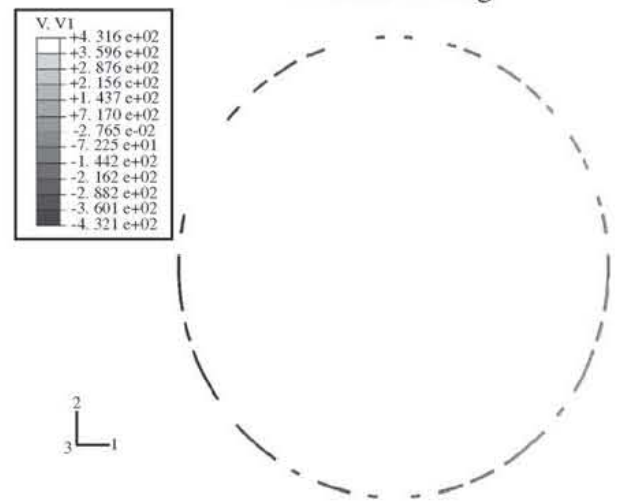

$\mathrm{Vo}_{\mathrm{o}}=450 \mathrm{~m} / \mathrm{s}-\mathrm{t}=4.8 \mathrm{E}-5 \mathrm{~s}-$ without necking

Fig. 12. Evolution of the number of fragments with the applied velocity. 


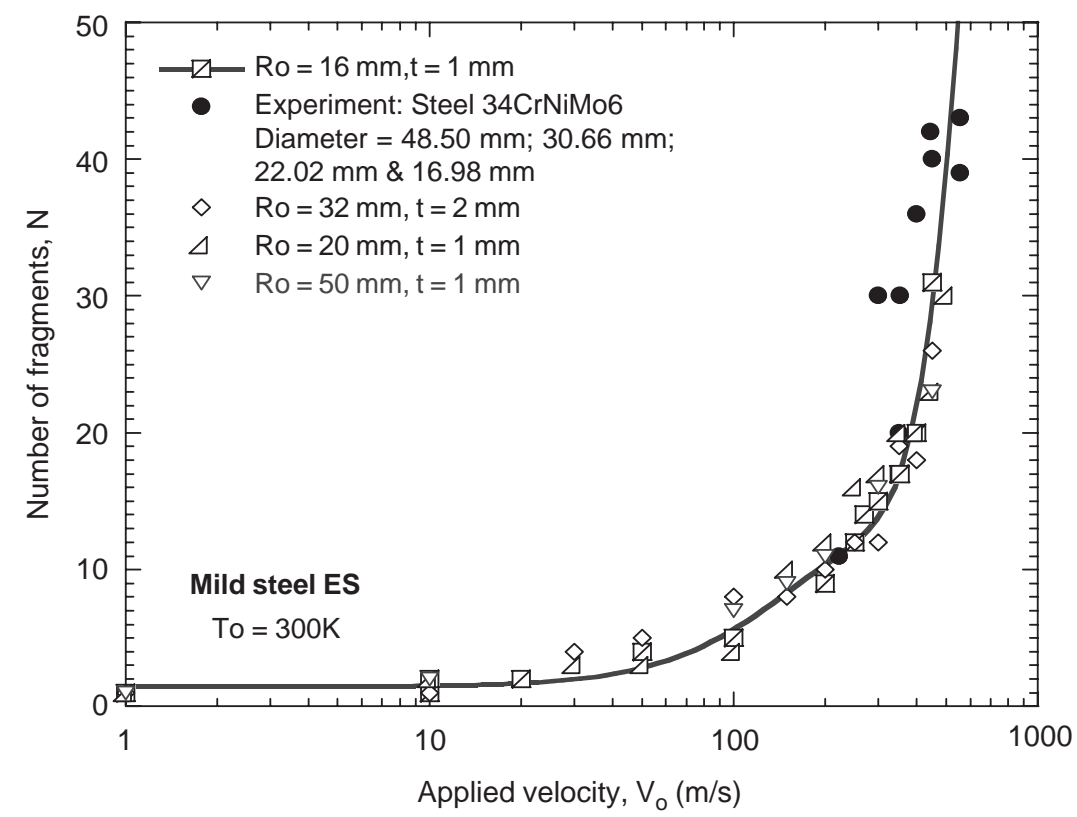

Fig. 13. Numerical predictions of number of fragments with applied velocity and different initial geometries. Comparison with experimental results [2].

A comparison of the numerical simulations for mild steel with the experimental results obtained in a $34 \mathrm{CrNiMo6}$ steel [2] is shown in Fig. 13. Since the adiabatic strain rate transition is similar in both metals (close to $\dot{\varepsilon}_{\text {adia }} \approx 100 \mathrm{~s}^{1}$ ), there is a good agreement in the evolution of the number of fragments with the velocity, tending to infinite (large number) at $V_{0}>300 \mathrm{~m} / \mathrm{s}$.

Not only are the number of fragments correctly predicted by simulations but also the failure mode. With large ductility the process of fragmentation is linked to necking. Thus, in our approach, the number of fragments is not affected by the failure criterion since the critical strain is relatively large in comparison with the level of strain corresponding to the loss of homogeneity, as discussed previously. In brittle material the failure appears quickly during the numerical simulations with no necking. Fig. 14 illustrates the good agreement with the failure mode obtained in experimental results in both ductile [6] and brittle materials [33].

Concerning the effect of $n_{0}$, we observed an increase of $N$ if $n_{0}$ decreases (Table A2 or Fig. 15a). However, the number of fragments $N$ in ductile material is limited and does not reach infinity value because of the characteristic necking length $l_{\text {neck }}$, Fig. 14. Thus, it is possible to define a minimum value using an initial radius $R_{0}$ and a characteristic length. For example, at 2 or $3 \mathrm{~mm}$, and $R_{0}=16 \mathrm{~mm}$, the minimum number of fragments at high applied velocity varies between $34 \leqslant N_{\min } \leqslant 50$ increasing with $R$ and decreasing with $l_{\text {neck }}$.

The $N$ increase for low value of $n_{0}$ is due to the definition of a brittle material behaviour, with a sudden instability $\left(\varepsilon_{\mathrm{c}} \approx n_{0}\right)$ and a small neck length $\bar{l}_{\text {neck }} \rightarrow 0$. The failure mode appears without necking (Fig. A1) leading to a rapid increase of the number of fragments.

As stated previously, differences in the number of fragments were analysed, not only in relation to the applied velocity but also in relation to two material properties: hardening and density. The effect of the first property was an increase of $N$ if $n_{0}$ decreased, Fig. 15a. Since hardening is connected to the CIV effect, a low value of the hardening exponent easily induces the trapping of the plastic wave and of plastic deformation on the internal radius. Moreover, according to the failure model adopted for the simulation, brittle behaviour of the material is then expected and the separation of fragments develops rapidly without necking, Fig. 14. Similar results were found by Mercier and Molinari [39] in a complete study using the linear perturbation technique. Regarding the effect of density on the number of fragments $N$, it was also observed that its increase leads to a rise of $N$, as anticipated previously, Fig. 15b. Again, the phenomenon is directly related to the plastic wave propagation since density, like hardening, directly affects the plastic wave speed $C_{\mathrm{p}}=\left(\rho^{1} \partial \sigma / \partial \varepsilon\right)^{1 / 2}$. Also, the numerical simulation predicted brittle failure/necking at large/small values of the density. Similar 

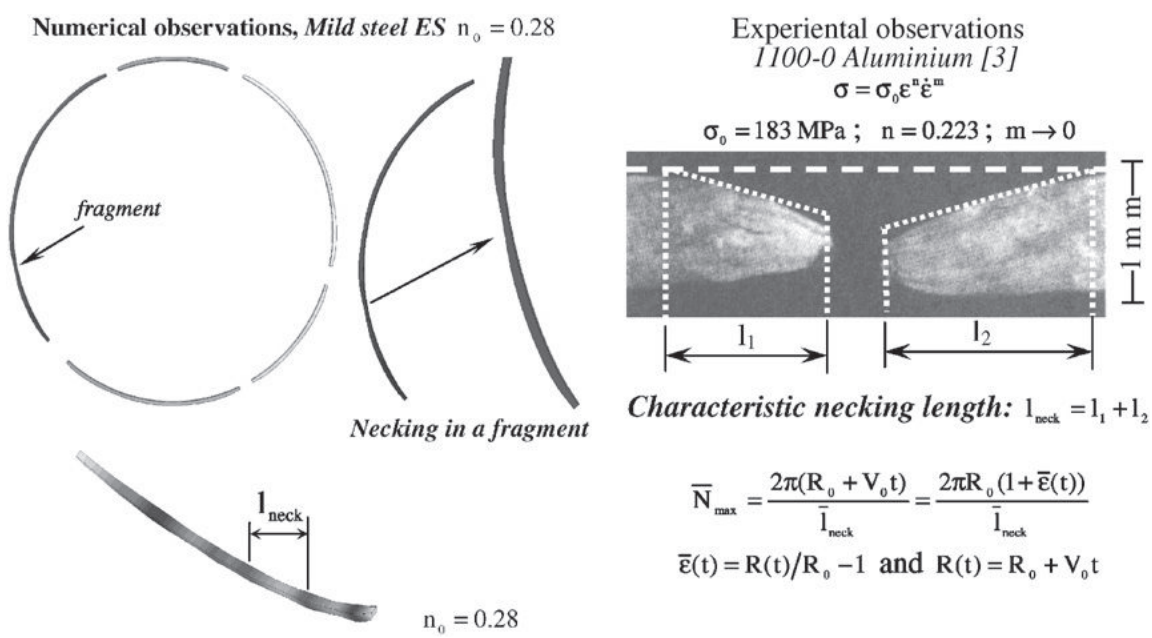

Fig. 14. Effect of $n_{0}$ on the failure mode at $V_{0} \quad 100 \mathrm{~m} / \mathrm{s}$.Comparison with experimental observation in ductile and brittle materials [6,33].
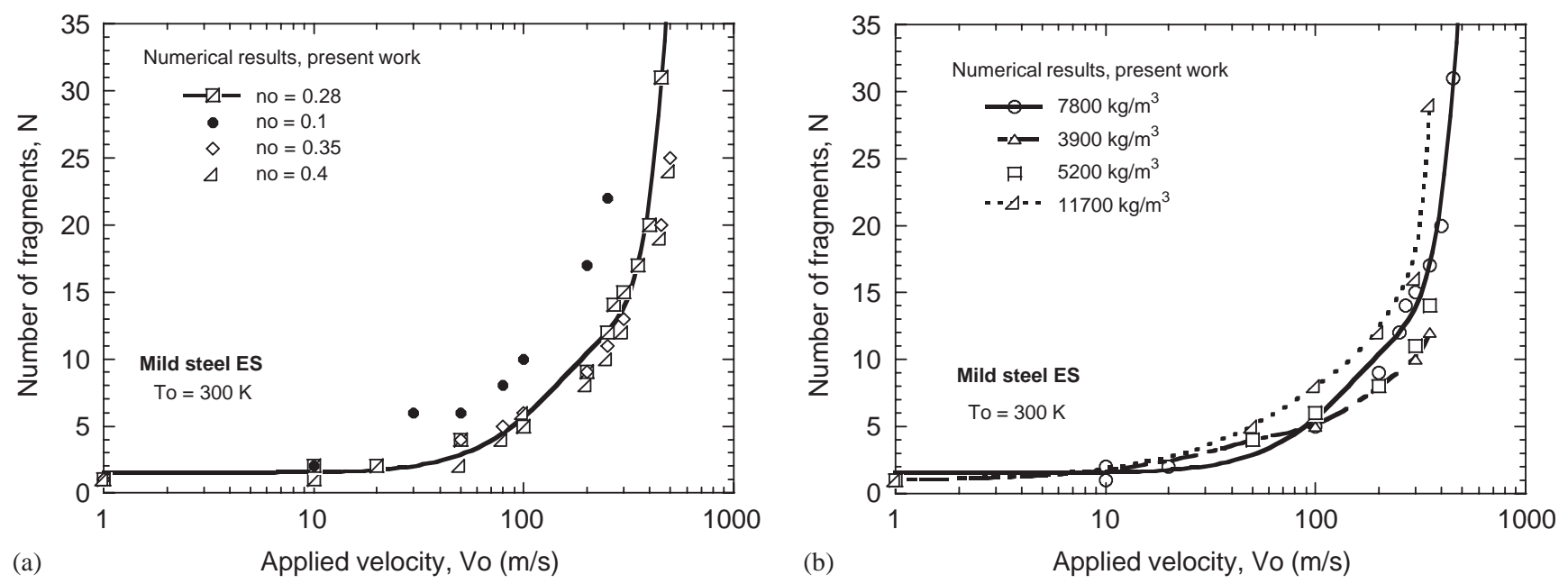

Fig. 15. (a) Effect of $n_{0}$ on the number of fragments $N$ and (b) analysis of the density of material $\rho$ on the number of fragments $N$.

observations had been observed during perforation tests of this material [12] and correlated to CIV using experimental results published by Wood [31]. In relation to the strain-rate exponent ( $m *$ in Eq. (5)), no effect on the number of fragments was found. Fig. A2 shows that this exponent primarily affects the stress level but not the strain rate transition.

Now our numerical results are compared with several experimental results and analytical predictions obtained in materials such as aluminium, Fig. 16. In the first comparison only the shape of the curve is analysed, and a good agreement is observed between our numerical results and experimental results obtained for aluminium and steel, notably in the number of fragments, this number again increasing at very high applied velocity.

In the following curves, the comparison is focused only on steel. Our numerical results obtained for a mild steel ES are compared with some experimental results obtained with a 34CrNiMo6 steel [2] and with others obtained by the linear perturbation analysis proposed by Mercier and Molinari [11] for different values of necking strain, Fig. 17. Our numerical predictions agree well with the experimental results. The disagreement with the linear perturbation approach appears only at very high imposed velocity since the number of 


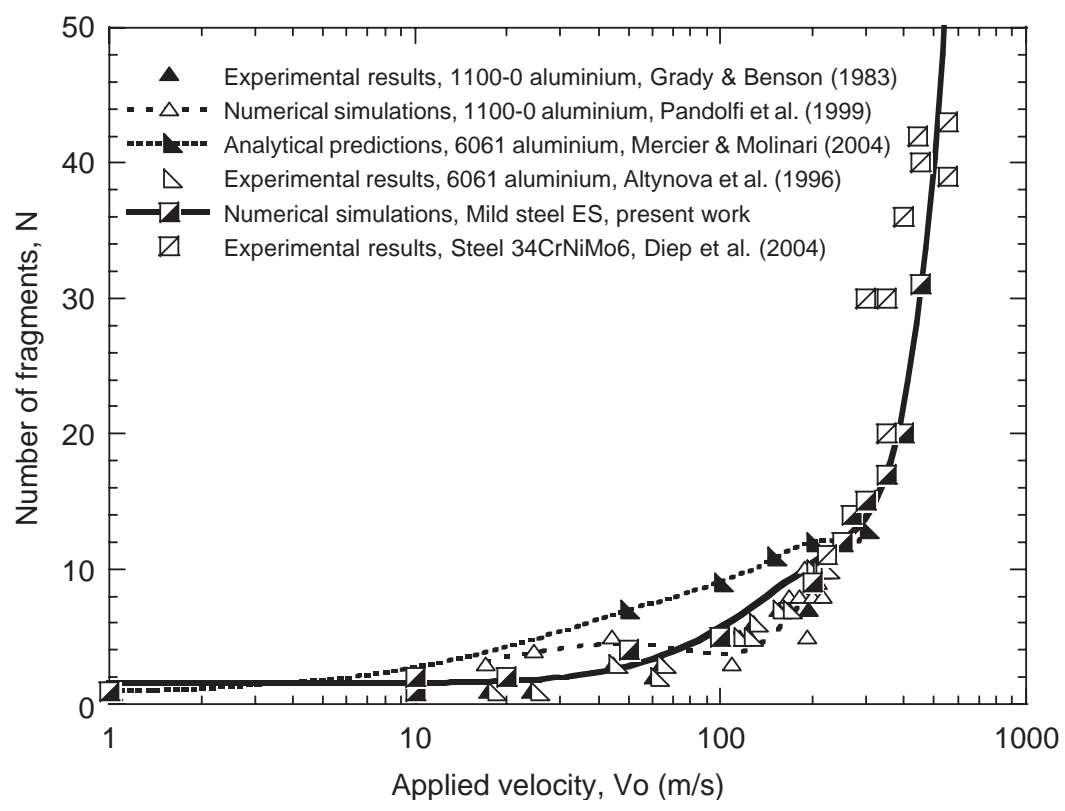

Fig. 16. Comparison of the curve of the increase in the number of fragments $N$ with applied velocity for different materials and models.

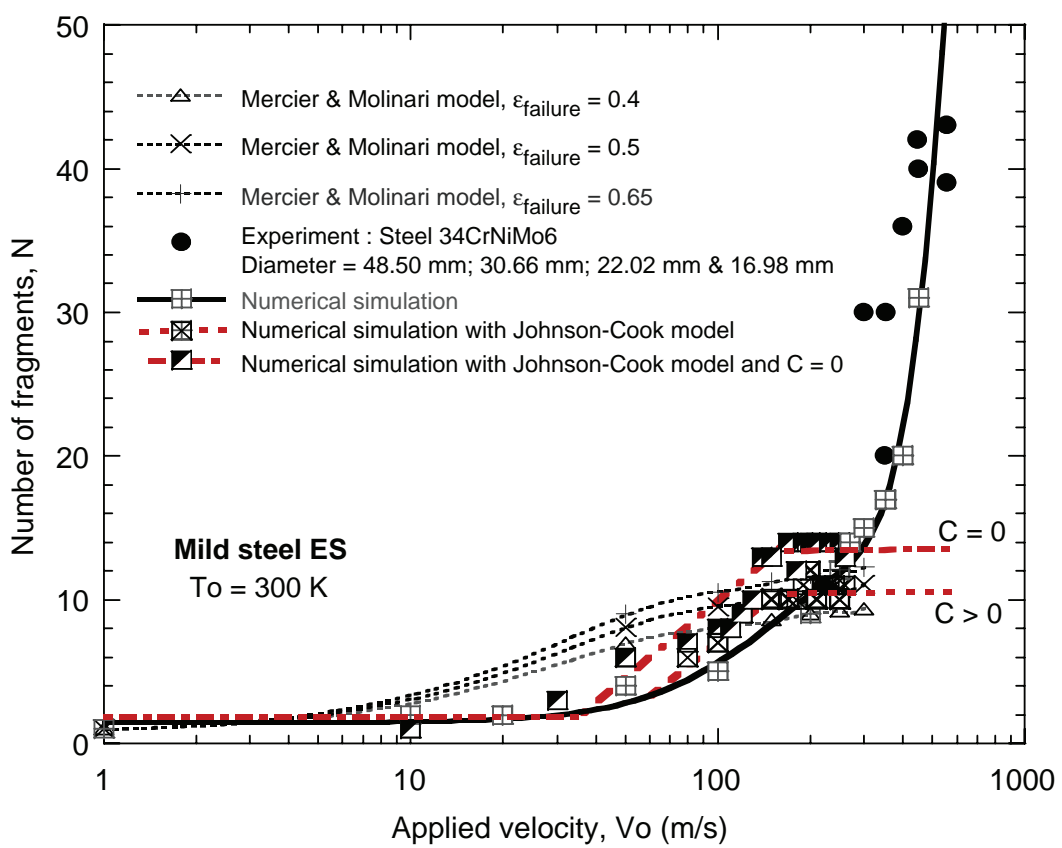

Fig. 17. Comparison of the number of fragments obtained by numerical simulation, by a linear perturbation approach [11], and experimental results obtained for steel [2].

fragments seems to stay constant. The main reason is that neither the strain rate sensitivity $(m \rightarrow 0)$ nor the thermal effect are introduced, which leads to a plateau of stress. In our case, the temperature increase at very high strain rate changes the value of $n$ (Eq. (7)), inducing an additional effect. However, the number of fragments is relatively close to that in the experiments at $V_{0} \leqslant 250 \mathrm{~m} / \mathrm{s}$. The third reason, is certainly connected to the omission of elastic and plastic wave propagation which induces a quick increase of the number of fragments $N$ if the CIV is reached or when the first neck appears. For example, in this mild steel ES, the CIV was estimated at about $100 \mathrm{~m} / \mathrm{s}$ in tensile state [8]. 

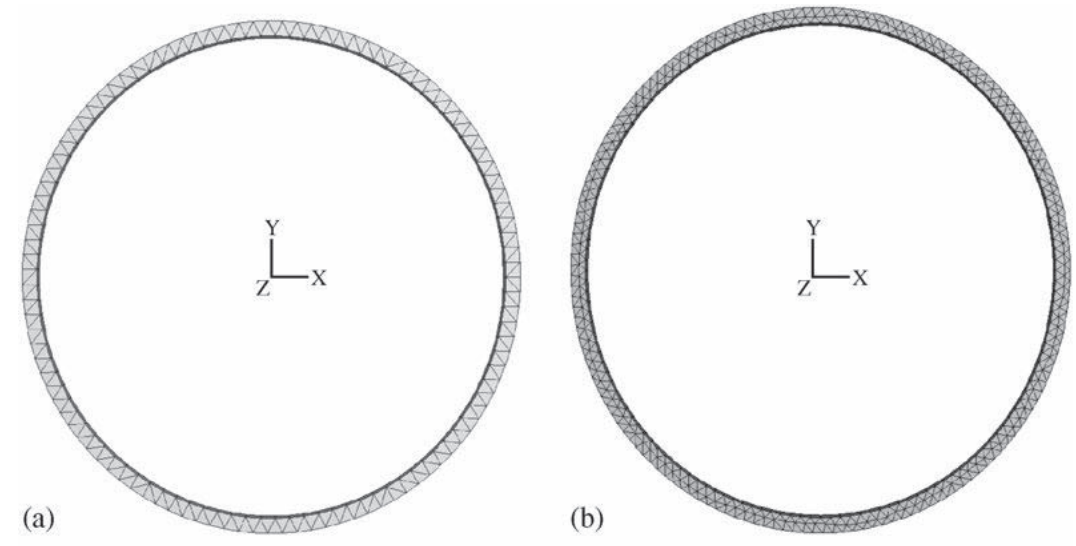

(b)

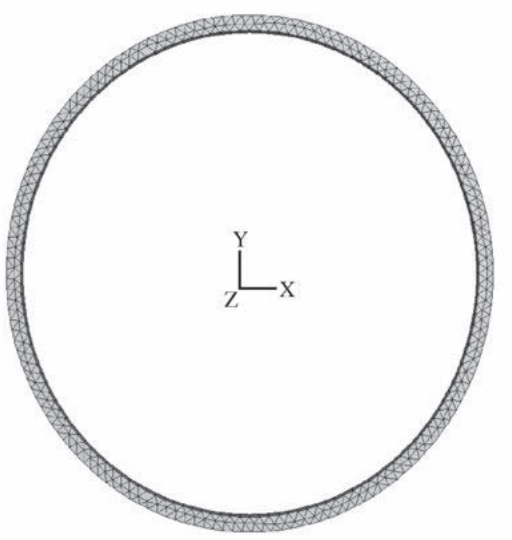

(c)

Fig. 18. (a) Fine mesh 1 used in numerical simulations; (b) fine mesh 2 and (c) super fine mesh 3.

To validate the previous results, an analysis was made of the mesh dependence. The results reported in the next section are only to validate the numerical results. Three complementary meshes were used with triangular elements as reported in [7] (Fig. 18).

\subsubsection{Mesh dependence solution}

In order to check the influence of the type of element and the mesh refinement on the results of the numerical simulations, three additional models were completed with 6-node triangular prisms (C3D6 in ABAQUS notation [22]) following the work of Pandolfi et al. [7]. Fig. 19 presents these meshes, with their elements/nodes equal to 208/416,601/906 and 1316/1488. The cubic element model was of 300 elements and 900 nodes.

The results obtained with the three meshes were similar: sudden increase of $N$ at above velocities $V_{0} \geqslant 300 \mathrm{~m} / \mathrm{s}$, so the numerical simulations obtained with the previous mesh (Fig. 7) may be generalised to explain the physical pattern which appears during ring expansion. The only difference was in the failure mode which is commonly closer to shear failure in the triangular element, due to the shape of the mesh. This type of element seems to be better able to define the ring expansion of brittle material which appears by shear or by crack but not by necking. With this type of element the shape of crack propagation is more realistic.

Using relatively simple numerical simulations of the process of fragmentation, a good prediction was obtained of the number of fragments with the applied velocity. Some physical parameters responsible for this effect also showed their influence. 


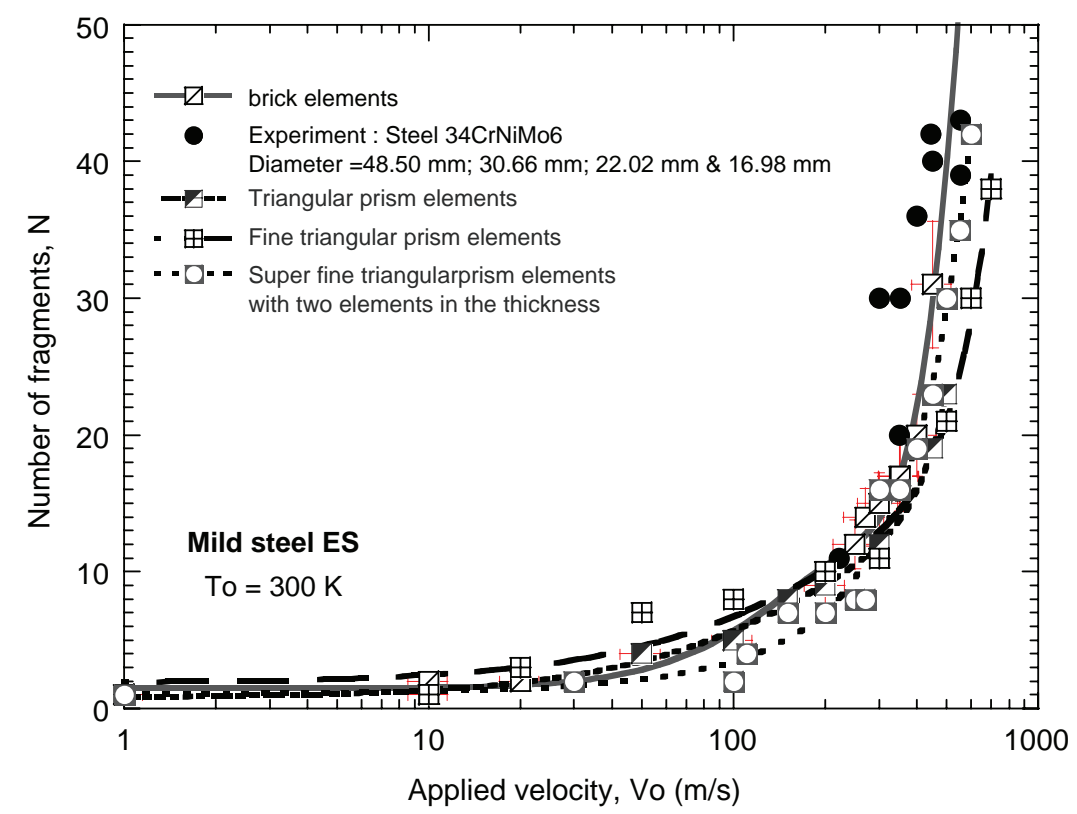

Fig. 19. Effect of the mesh on the numerical predictions of the number of fragments $N$.

\section{Conclusion}

Using a thermoviscoplastic model that coupled thermal and viscosity effects with an original integration algorithm, the problem of ring expansion was examined. Fracture was also analysed using a critical strain level based on the CIV and the Considère criterion. The numerical calculations were made with ABAQUS/Explicit in adiabatic conditions, including elastic and plastic wave propagation. This process governs the rise of the number of fragments at very high applied velocity since the slower plastic wave propagation during the process induces unloading zones with reflected elastic waves that provoke local necking. However, the necking instability is essentially geometrical in nature at low and intermediate applied velocity.

The numerical analysis has also shown the effect of physical parameters such as hardening, material density and sensitivity to strain rate, and also the geometric effects in the internal and external radius. Only $n_{0}, \rho$ and the transition of strain rate sensitivity seem to affect the prediction of the number of fragments. The effect of temperature was reflected in the hardening coefficient which decreases during plastic deformation when the plastic work is converted into heat. In fact, the observations are similar to those of the instability study [40] in which hardening stabilises the initiation of instability, in contrast to the softening effect of temperature.

The proposed model confirms the validity of the constitutive model and the algorithm used previously to model processes such as dynamic tension, perforation, shear and buckling. Complementary to the effort made on the development sophisticated elements [7] or mesh refinement [7,34], it is clear that a strong point of an appropriate simulation is the constitutive relation used to define the thermoviscoplastic behaviour of the material $[34,41]$.

\section{Acknowledgements}

The authors thank Pr. J. Fernández-Sáez for his contribution to the development of the thermoviscoplastic algorithm, Pr. J.R. Klepaczko for the discussions and comments, Dr. S. Mercier and Pr. A. Molinari for their contribution in the analytical prediction using a perturbation analyses and many discussions in this field.

\section{Appendix A}

Constant used to define the thermoviscoplastic behaviour of our mild steel and definition of the number of fragment with applied velocity, Tables A1 and A2. 
Table A1

Constants used during numerical simulations

Our constitutive relation

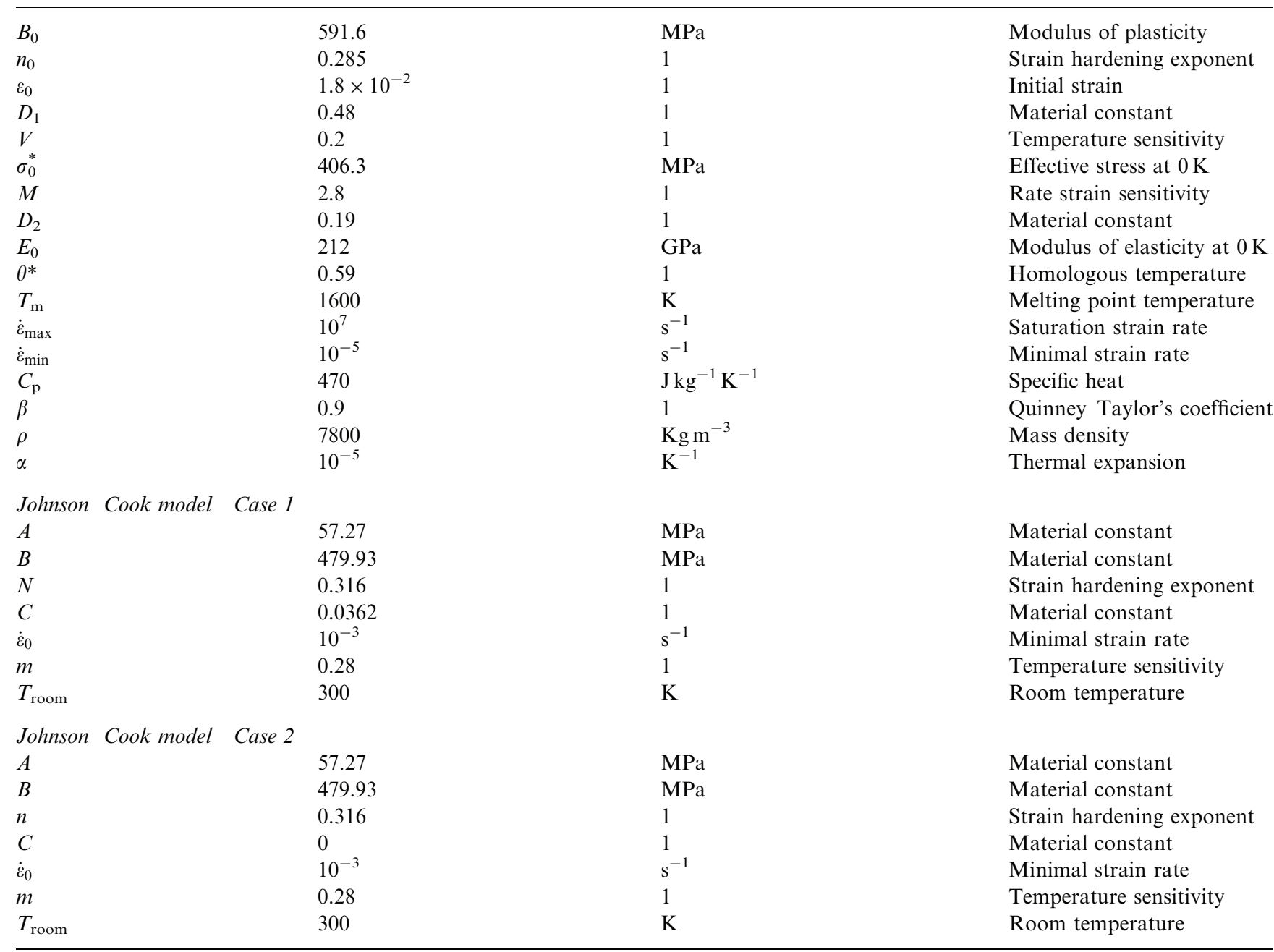

Table A2

Effect of the geometry on the number of fragments at different applied velocities

\begin{tabular}{|c|c|c|c|c|c|c|c|c|c|c|c|c|c|c|c|c|}
\hline$V_{\mathrm{o}}(\mathrm{m} / \mathrm{s})$ & $n_{0}$ & $R_{0}$ & $R_{1}$ & $N$ & $n_{0}$ & $R_{0}$ & $R_{1}$ & $N$ & $n_{0}$ & $R_{0}$ & $R_{1}$ & $N$ & $n_{0}$ & $R_{0}$ & $R_{1}$ & $N$ \\
\hline 1 & 0.28 & 16 & 17 & 1 & 0.28 & 20 & 21 & 1 & 0.28 & 32 & 34 & 1 & 0.28 & 50 & 51 & 1 \\
\hline 10 & & & & 2 & & & & 2 & & & & 1 & & & & 2 \\
\hline 20 & & & & 2 & & & & $\mathrm{NC}$ & & & & $\mathrm{NC}$ & & & & $\mathrm{NC}$ \\
\hline 30 & & & & $\mathrm{NC}$ & & & & $\mathrm{NC}$ & & & & 4 & & & & $\mathrm{NC}$ \\
\hline 50 & & & & 4 & & & & $\mathrm{NC}$ & & & & 5 & & & & $\mathrm{NC}$ \\
\hline 100 & & & & 5 & & & & 4 & & & & 8 & & & & 7 \\
\hline 150 & & & & 9 & & & & 10 & & & & 8 & & & & 9 \\
\hline 170 & & & & $\mathrm{NC}$ & & & & $\mathrm{NC}$ & & & & $\mathrm{NC}$ & & & & $\mathrm{NC}$ \\
\hline 180 & & & & 9 & & & & $\mathrm{NC}$ & & & & $\mathrm{NC}$ & & & & NC \\
\hline 200 & & & & 9 & & & & 12 & & & & 10 & & & & 11 \\
\hline 250 & & & & 12 & & & & 16 & & & & 12 & & & & $\mathrm{NC}$ \\
\hline 270 & & & & 14 & & & & $\mathrm{NC}$ & & & & $\mathrm{NC}$ & & & & $\mathrm{NC}$ \\
\hline 300 & & & & 15 & & & & 17 & & & & 12 & & & & 16 \\
\hline 350 & & & & 17 & & & & 20 & & & & 19 & & & & $\mathrm{NC}$ \\
\hline 352 & & & & 17 & & & & $\mathrm{NC}$ & & & & $\mathrm{NC}$ & & & & $\mathrm{NC}$ \\
\hline
\end{tabular}


Table A2 (continued)

\begin{tabular}{|c|c|c|c|c|c|c|c|c|c|c|c|c|c|c|c|c|}
\hline$V_{\mathrm{o}}(\mathrm{m} / \mathrm{s})$ & $n_{0}$ & $R_{0}$ & $R_{1}$ & $N$ & $n_{0}$ & $R_{0}$ & $R_{1}$ & $N$ & $n_{0}$ & $R_{0}$ & $R_{1}$ & $N$ & $n_{0}$ & $R_{0}$ & $R_{1}$ & $N$ \\
\hline 400 & & & & 20 & & & & 20 & & & & 18 & & & & $\mathrm{NC}$ \\
\hline 450 & & & & 31 & & & & 23 & & & & 26 & & & & 23 \\
\hline 500 & & & & $\mathrm{NC}$ & & & & $\mathrm{NC}$ & & & & $\mathrm{NC}$ & & & & $\mathrm{NC}$ \\
\hline
\end{tabular}

NC, not calculated.

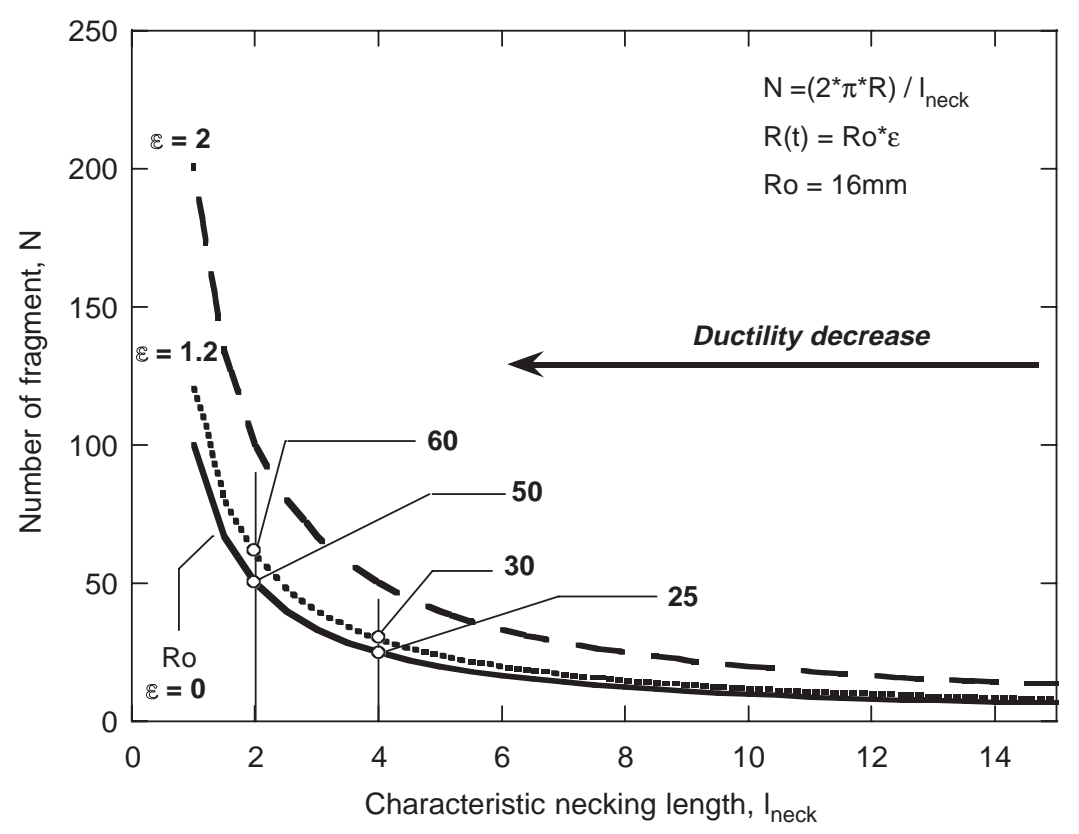

Fig. A1. Effect of the characteristic length during ring expansion on the number of fragment.

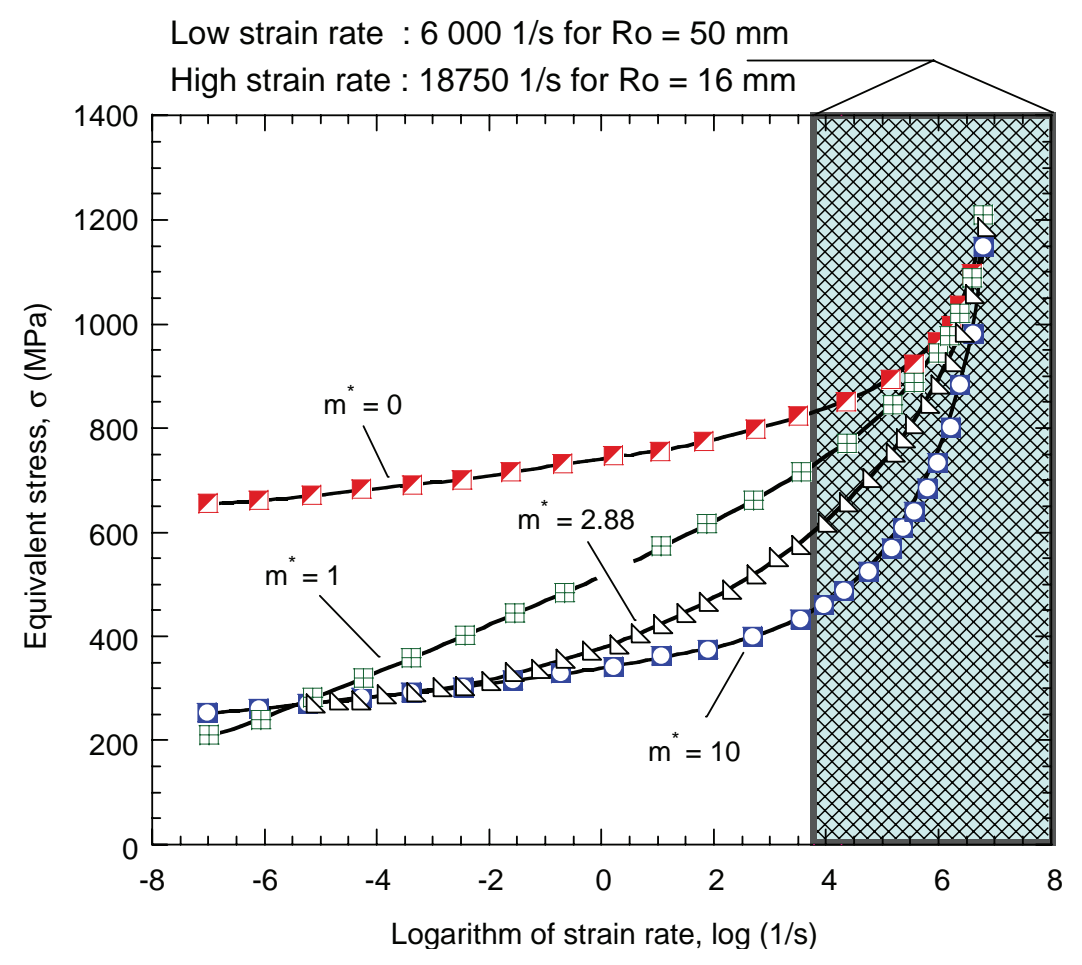

Fig. A2. Effect of the coefficient of strain rate sensitivity $m^{*}$ on the flow stress. 


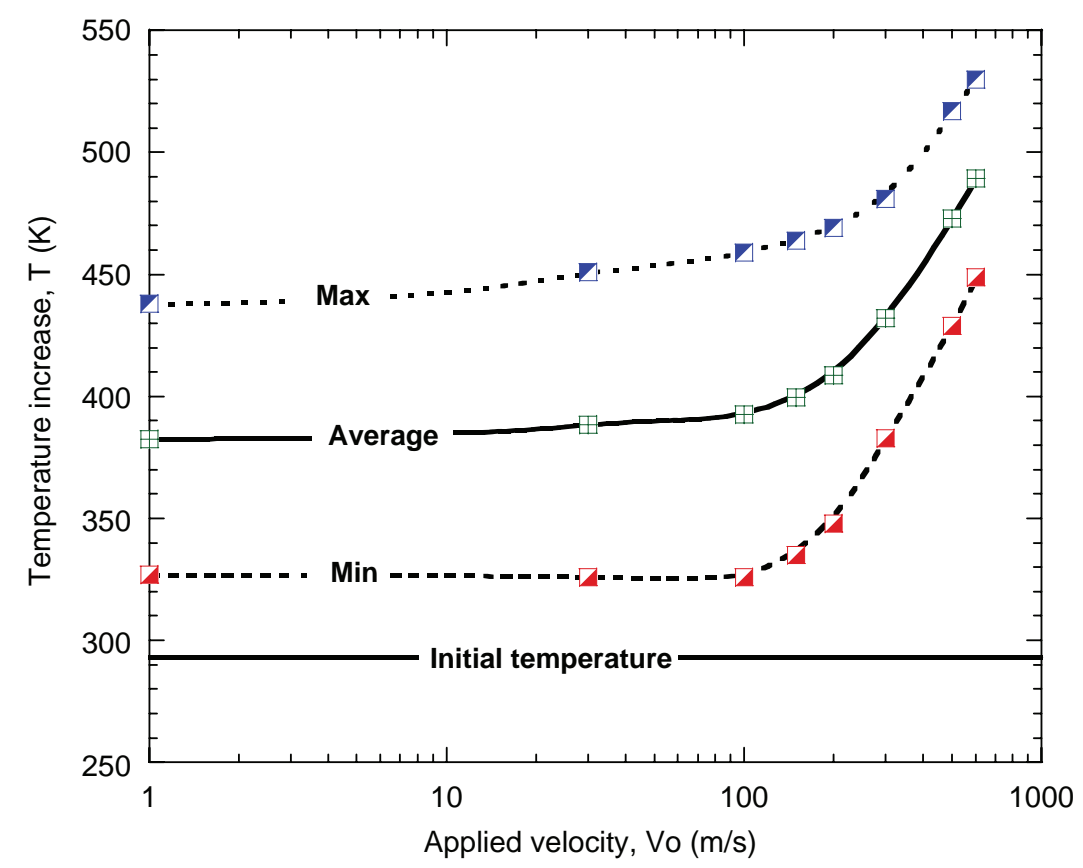

Fig. A3. Temperature increase during ring expansion at different applied velocities.

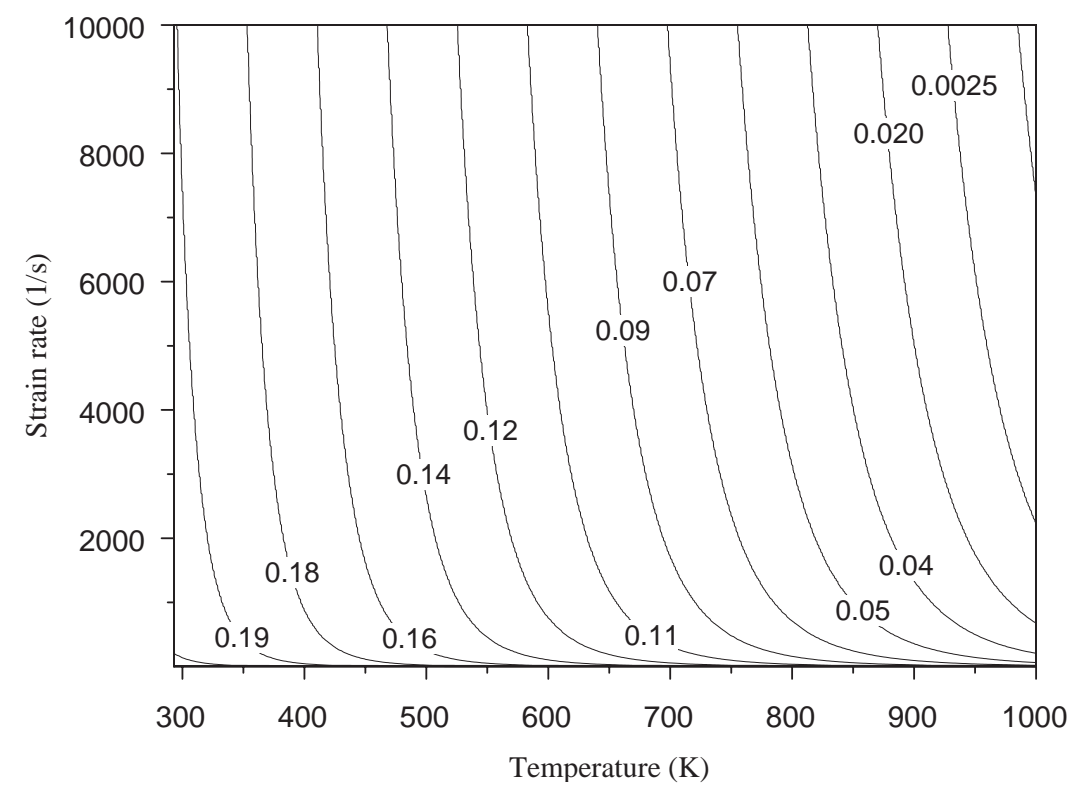

Fig. A4. Evolution of the hardening exponent $n(\dot{\varepsilon}, T)$ with strain rate and temperature during ring expansion.

Effect of the characteristic length, Fig. 14, on the number of fragment and effect of the constant $m^{*}$, Eq. (5), on the definition of the strain rate sensitivity. A large value of $m^{*}$ allows to define the strain rate sensitivity of steel with high yield stress or Aluminium alloys (no strain rate sensitivity until $\dot{\varepsilon} \approx 10^{3} \mathrm{~s}{ }^{1}$ (Figs. A1-A6). 

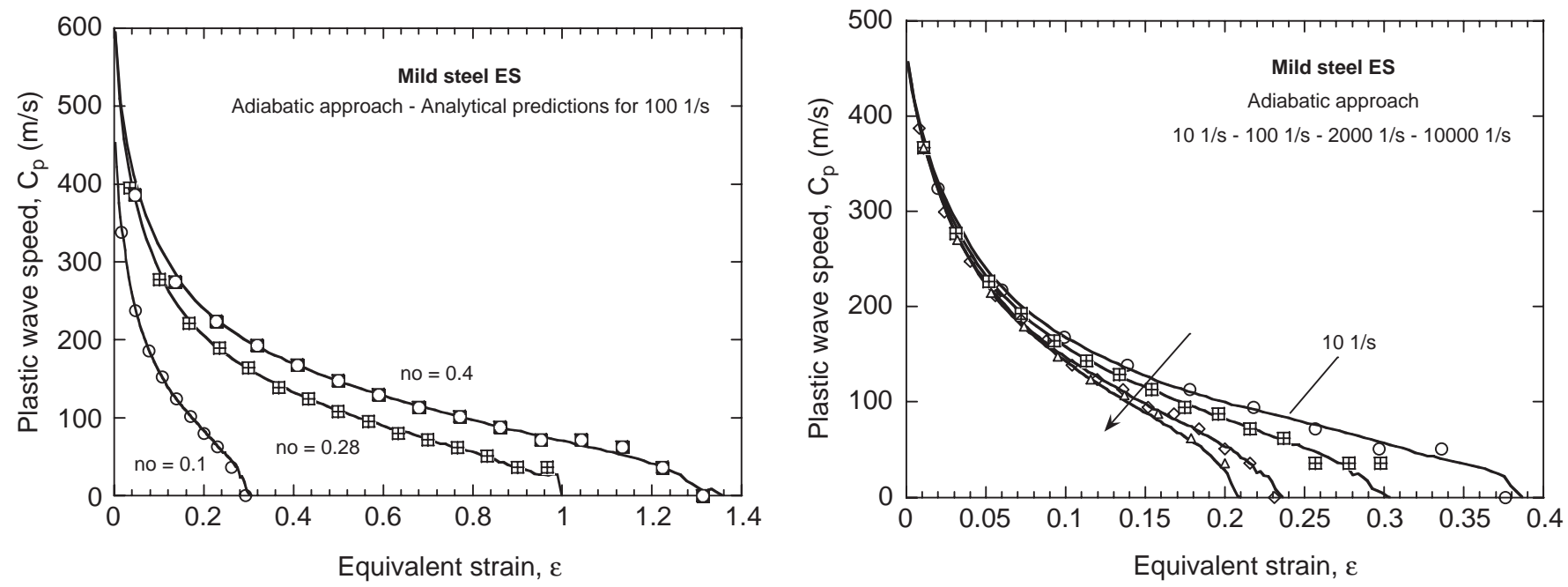

Fig. A5. Evolution of the plastic wave speed for different values of $n_{0}$ and strain rates

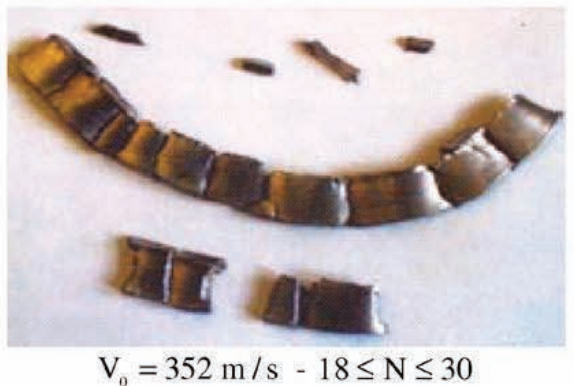

$$
\therefore \therefore \therefore \therefore
$$

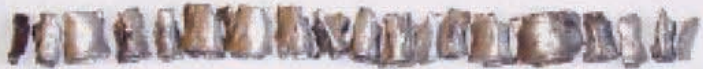

$$
\mathrm{V}_{0}=352 \mathrm{~m} / \mathrm{s}-28 \leq \mathrm{N} \leq 37
$$

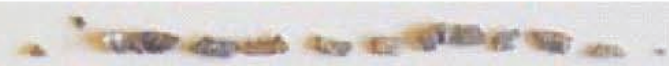

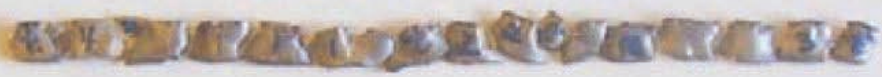

$\mathrm{V}_{0}=352 \mathrm{~m} / \mathrm{s}-39 \leq \mathrm{N} \leq 43$

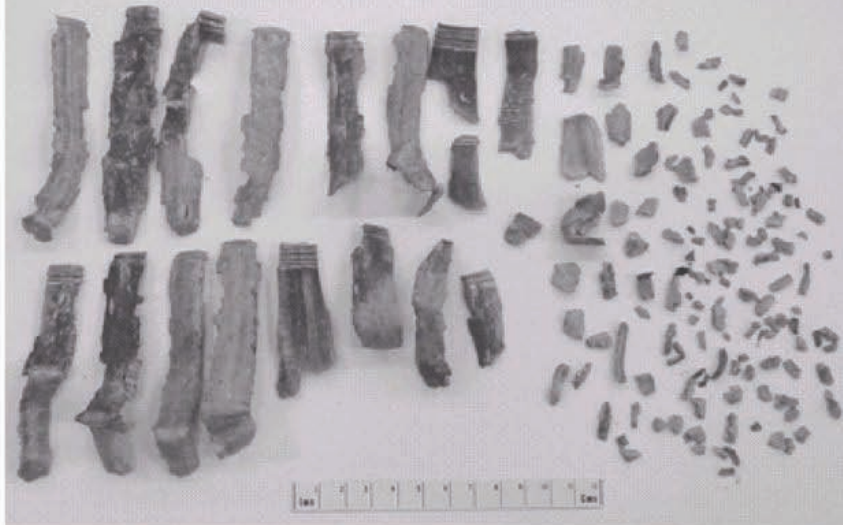

Detonation velocity $1500 \leq \mathrm{V}_{\mathrm{D}} \leq 5000 \mathrm{~m} / \mathrm{s}$

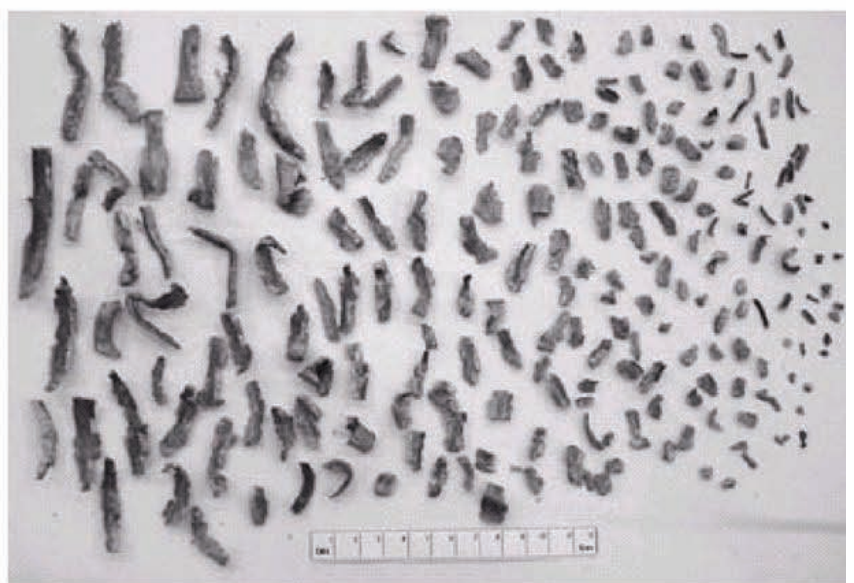

Detonation velocity $V_{D}=8100 \mathrm{~m} / \mathrm{s}$

Fig. A6. Effect of applied velocity on the number of fragments $N[2,44]$. 
Temperature increase during ring expansion for different applied velocity inducing a decrease of the hardening $n(\dot{\varepsilon}, T)$ during loading, Fig. A4.

\section{References}

[1] Hu X, Daehn GS. Effect of velocity on flow localization in tension. Acta Mater 1996;44:1021 33.

[2] Diep QB, Moxnes JF, Nevstad G. Fragmentation of projectiles and steel rings using numerical 3D simulations, In: The 21th International Symposium of Ballistics, April 2004, Adelaide, Australia.

[3] Triantafyllidis N, Waldenmyer JR. Onset of necking in electro magnetically formed rings. J Mech.Phys Solids 2004;52:2127 48.

[4] Altinova M, Hu X, Dahen GS. Increased ductility in high velocity electromagnetic ring expansion. Metall Trans A 1996;27: 183744.

[5] Niordson FL. A unit for testing materials at high strain rates. Exp Mech 1965;5:29 32.

[6] Grady DE, Benson DA. Fragmentation of metal rings by electromagnetic loading. Exp Mech 1983;12:393 400.

[7] Pandolfi A, Krysl P, Ortiz M. Finite element simulation of ring expansion and fragmentation. Int J Fract 1999;95:279 97.

[8] Rusinek A, Zaera R, Klepaczko JR, Cheriguene R. Analysis of inertia and scale effects on dynamic neck formation during tension of sheet steel. Acta Mater 2005;53:5387 400.

[9] Rusinek A, Klepaczko JR. Shear testing of a sheet steel at wide range of strain rates and a constitutive relation with strain rate and temperature dependence of the flow stress. Int J Plast 2000;17:87 115.

[10] Zaera R, Fernández Sáez J. An implicit consistent algorithm for the integration of thermoviscoplastic constitutive equations in adiabatic conditions and finite deformations. Int J Solids Struct 2006;43:1594 612.

[11] Mercier S, Molinari A. Predictions of bifurcation and instabilities during dynamic extension. Int J Solids Struct 2003;40:1995 2016.

[12] Rusinek A. Modélisation thermoviscoplastique d'une nuance de tôle d'acier aux grandes vitesses de déformation. Etude expérimentale et numérique du cisaillement, de la traction et de la perforation, Thèse de Doctorat de l'Université de Metz, 2000.

[13] Klepaczko JR. Modelling of structural evolution at medium and high strain rates, FCC and BCC metals. In: Ammann WJ, Liu WK, Studer JA, Zimmermann T, editors. Impact: effects of fast transient loading. Rotterdam/Brookfield: A.A. Balkema; 1988 . p. 335.

[14] Klepaczko JR. Thermally activated flow and strain history effects for some polycrystalline FCC metals. Mater Sci Eng 1975;18:121.

[15] Kocks UF, Argon AS, Ashby MF. Thermodynamics and kinetics of slip. Oxford: Pergamon Press; 1975.

[16] Hodowany J, Ravichandran G, Rosakis AJ, Rosakis P. Partition of plastic work into heat stored energy in metals. Exp Mech 2000;40:113 23.

[17] Macdougall D. Determination of the plastic work converted to heat using radiometry. Exp Mech 2000;40:298 306.

[18] Simo JC, Hughes TJR. Computational inelasticity. New York: Springer; 1998 [chapter 8].

[19] Perzyna P. The constitutive equations for rate sensitive plastic materials. Q Appl Math 1963;20:321 32.

[20] Wang WM, Sluys LJ, de Borst R. Viscoplasticity for instabilities due to strain softening and strain rate softening. Int J Numer Methods Eng 1997;40:3839 64.

[21] Zaera R, Rusinek A, Klepaczko JR, Navarro C. Dynamic behavior of steel sheets: a thermoviscoplastic approach for direct applications in numerical simulations, Technical meeting DYMAT 2004.

[22] ABAQUS/Explicit user manual, vol. I and II, version 6.4.1, Hibbitt, Karlsson and Sorensen Inc., 2004.

[23] Larson M, Needlemen A, Tvergaard V, Storakers B. Instability and failure of internally pressurized ductile metal cylinders. Internal report, Division of Engineering, Brown University, Providence, June 1981.

[24] Han JB, Tvergaard V. Effect of inertia on the necking behaviour of ring specimens under rapid axial expansion. Eur J Mech A/Solids 1995; 14:287 307.

[25] Sorensen NJ, Freund LB. Unstable neck formation in a ductile ring subjected to impulsive radial loading. Int J Solids Struct 2000;37:2265 83.

[26] Rusinek A, Klepaczko JR. Effect of adiabatic heating in some processes of deformation. In: Chiba A, Tanimura S, Hokamoto K, editors. Impact engineering and application, vol. 2. Elsevier Science Ltd.; 2001. p. 5416.

[27] Wood WW. Experimental mechanics at velocity extremes very high strain rates. Exp Mech 1965;5:361 71.

[28] Nilson K. Effects of elastic unloading on multiple necking in tensile bars. Int J Impact Eng 2004;30:1353 67.

[29] Guduru PR, Freund LB. The dynamics of multiple neck formation and fragmentation in high rate extension of ductile materials. Int $\mathbf{J}$ Solids Struct 2002;39:5615 32 .

[30] Clark DS, Wood WW. The tensile impact properties of some metals and alloys. Proc ASTM 1950;42:45 52.

[31] Wood WW. Experimental mechanics at velocity extremes very high strain rates. In: SESA Spring meeting held in Denver, Colorado, 1965. p. 16.

[32] Considère AG. L'emploi du fer de l'acier dans les constructions, Mémoire no. 34. Ann Ponts et Chaussées, Paris 1885:574 5.

[33] Singh M, Suneja HR, Bola MS, Prakash S. Dynamic tensile deformation and fracture of metal cylinders at high strain rates. Int J Impact Eng 2002;27:939 54.

[34] Becker R. Ring fragmentation predictions using the Gurson model with material stability conditions as failure criteria. Int J Solids Struct 2002;39:3555 80 .

[35] Drucker DC. A definition of stable inelastic material. J Appl Mech, Trans ASME 1959;81:101 6 .

[36] Ortiz M, Pandolfi A. A class of cohesive elements for the simulation of three dimensional crack propagation. Int J Numer Methods Eng 1998.

[37] Camacho GT, Ortiz M. Computational modelling of impact damage in brittle materials. Int J Solids Struct 1996;33:2899 938. 
[38] Camacho GT, Ortiz M. Adaptative Lagrangian modelling of ballistic penetration of metallic targets. Comput Methods Appl Mech Eng 1997;142:269 301.

[39] Mercier S, Molinari A. Analysis of multiple necking in rings under rapid radial expansion. Int J Impact Eng 2004;30:403 19.

[40] Fressengeas C, Molinari A. Instability and Localization of plastic flow in shear at high strain rates. J Mech Phys Solids 1987;33:185 211.

[41] Nilsson K. Effects of elastic unloading on multiple necking in tensile bars. Int J Impact Eng 2004;30:1353 67.

[42] Winnicki A, Pearce CJ, Bicanic N. Viscoplastic Hoffman consistency model for concrete. Comput Struct 2001;79:7 19.

[43] Heeres OM, Suiker ASJ, de Borst R. A comparison between the Perzyna viscoplastic model and the consistency viscoplastic model. Eur J Mech A solid 2002;21:1 12.

[44] Dawson S, Edwards M. Microstructure of steel fragments produced by explosive charges. In: Burman N, Anderson J, Katselis G, editors. In: Proceedings of the 21st international symposium on ballistics, DSTO, Australia, vol. 1. 2004. p. 28996.

[45] Nilsson K. Effects of inertia on dynamic neck formation in tensile bars. Eur J Mech A/Solids 2001;20:713 29.

[46] Xu X, Needleman A. Numerical simulation of fast crak growth in brittle solids. J Mech Phys Solids 1994;42:1397 434. 